\title{
Microbiome and ecotypic adaption of Holcus lanatus (L.) to extremes of its soil pH range, investigated through transcriptome sequencing
}

\author{
Ellen Young, Manus Carey, Andrew A. Meharg and Caroline Meharg ${ }^{*}$ (D)
}

\begin{abstract}
Background: Plants can adapt to edaphic stress, such as nutrient deficiency, toxicity and biotic challenges, by controlled transcriptomic responses, including microbiome interactions. Traditionally studied in model plant species with controlled microbiota inoculation treatments, molecular plant-microbiome interactions can be functionally investigated via RNA-Seq. Complex, natural plant-microbiome studies are limited, typically focusing on microbial rRNA and omitting functional microbiome investigations, presenting a fundamental knowledge gap. Here, root and shoot meta-transcriptome analyses, in tandem with shoot elemental content and root staining, were employed to investigate transcriptome responses in the wild grass Holcus lanatus and its associated natural multi-species eukaryotic microbiome. A full factorial reciprocal soil transplant experiment was employed, using plant ecotypes from two widely contrasting natural habitats, acid bog and limestone quarry soil, to investigate naturally occurring, and ecologically meaningful, edaphically driven molecular plant-microbiome interactions.

Results: Arbuscular mycorrhizal (AM) and non-AM fungal colonization was detected in roots in both soils. Staining showed greater levels of non-AM fungi, and transcriptomics indicated a predominance of Ascomycota-annotated genes. Roots in acid bog soil were dominated by Phialocephala-annotated transcripts, a putative growth-promoting endophyte, potentially involved in N nutrition and ion homeostasis. Limestone roots in acid bog soil had greater expression of other Ascomycete genera and Oomycetes and lower expression of Phialocephala-annotated transcripts compared to acid ecotype roots, which corresponded with reduced induction of pathogen defense processes, particularly lignin biosynthesis in limestone ecotypes. Ascomycota dominated in shoots and limestone soil roots, but Phialocephala-annotated transcripts were insignificant, and no single Ascomycete genus dominated. Fusarium-annotated transcripts were the most common genus in shoots, with Colletotrichum and Rhizophagus (AM fungi) most numerous in limestone soil roots. The latter coincided with upregulation of plant genes involved in $\mathrm{AM}$ symbiosis initiation and $\mathrm{AM}$-based $\mathrm{P}$ acquisition in an environment where $\mathrm{P}$ availability is low.

Conclusions: Meta-transcriptome analyses provided novel insights into H. lanatus transcriptome responses, associated eukaryotic microbiota functions and taxonomic community composition. Significant edaphic and plant ecotype effects were identified, demonstrating that meta-transcriptome-based functional analysis is a powerful tool for the study of natural plant-microbiome interactions.
\end{abstract}

Keywords: Holcus lanatus, Eukaryotic microbiome, Meta-transcriptomics, Community composition, Gene expression, Gene function, Edaphic stress

\footnotetext{
* Correspondence: caroline.meharg@qub.ac.uk

Institute for Global Food Security, Queens University Belfast, David Keir

Building, Belfast BT9 5BN, Northern Ireland, UK
}

(c) The Author(s). 2018 Open Access This article is distributed under the terms of the Creative Commons Attribution 4.0 International License (http://creativecommons.org/licenses/by/4.0/), which permits unrestricted use, distribution, and reproduction in any medium, provided you give appropriate credit to the original author(s) and the source, provide a link to the Creative Commons license, and indicate if changes were made. The Creative Commons Public Domain Dedication waiver (http://creativecommons.org/publicdomain/zero/1.0/) applies to the data made available in this article, unless otherwise stated. 


\section{Background}

Extremes of soil pH present strong selection pressures, particularly relating to nutrient availabilities. Soils with $\mathrm{pH}<5.5$ cause $\mathrm{Al}, \mathrm{Fe}, \mathrm{Mn}$ and $\mathrm{H}$ toxicities and simultaneous $\mathrm{P}, \mathrm{N}$ and base cation deficiencies, resulting in inhibition of root growth and poor productivity [1]. Neutral to alkaline soils are limited in Fe, Mn and P availability [1]. Decreasing soil bacterial activity with increasing soil acidity regulates $\mathrm{N}$ availability, with nitrate dominating at neutral to high $\mathrm{pHs}$, ammonium at low $\mathrm{pHs}$, and amino acids at extreme low $\mathrm{pH}$ [2]. Soil pH also influences edaphic bacterial and fungal community compositions, including root-colonizing arbuscular mycorrhiza (AM) and non-AM fungi, with disparate edaphic conditions driving differences in root colonization within the same host species [3-5]. Non-AM fungi are abundant in all soils, including acid peatland [4], while AM fungi have been shown to occur at lower frequency in lower $\mathrm{pH}$ and waterlogged soils [5].

Components of the soil microbiome interact with plants in beneficial, neutral or pathogenic manners. AM and root endophytes have been shown to increase nutrient uptake, particularly P [6-8], and plants can actively encourage AM fungal colonization under low nutrient stress conditions [9]. Equally, fungi can influence gene expression in plants. Fungal induction of plant lipoxygenase and its associated pathway has been linked to fungal-mediated tolerance traits, and plant defenses primed or boosted by fungi include antioxidant, phenol and flavonoid production and toxic metal chelation [10-13]. Fungal colonization can improve plant resistance to pathogen infection [13], salt stress [12] and toxic metal(loid) stress $[11,13,14]$, the latter of which is common on acidic soils due to higher bioavailability of $\mathrm{Al}, \mathrm{Fe}$ and $\mathrm{Mn}[2,15]$. Pathogenic fungal elicitors cause initiation of plant defensive responses upon detection [16, 17], but necrotrophic fungi can in turn manipulate plant defenses to facilitate initial infection, with further manipulation of the oxidative burst response to continue colonization [18].

Given these interactions, characterizing hostmicrobiome relationships therefore require analysis of gene expression and functional responses from both components, plant and fungal. Furthermore, given that plant-microbiome interactions are strongly influenced by edaphic factors, they can be considered key to the understanding of plant edaphic stress response and crucial for our understanding of plant adaptation to environmental change [19]. Assessment of soil and root microbiomes has traditionally been taxonomy based, using amplicon sequencing of the rRNA operon [20, 21], which, as normally DNA based, cannot distinguish between metabolically active and dormant components of the plant-microbiome system or provide information about functional roles. Furthermore, as plant- microbiome interactions involve multiple microbial species, there must be a high level of functional redundancy, with a range of species fulfilling the same or similar functions in different environmental niches, which a gene expression-based investigation can address. For prokaryotes, PICRUSt (phylogenetic investigation of communities by reconstruction of unobserved states) analysis [22] allows inference of metagenomes and metabolic potential from amplicon sequencing data, but similar analyses are not available for fungi and other eukaryotic microbes. Even for prokaryotes, gene expression data is the only way to measure true activity. As next-generation sequencing (NGS), via sequencing of polyA-selected RNAs, provides a technology that can capture gene expression of all eukaryotes in any one sample, this is a convenient way to investigate host and eukaryotic microbiomes in tandem. Published annotated genomes and protein databases for plants, fungi and protists facilitate a functional meta-transcriptomic approach that can uncover eukaryotic microbiome function in the context of plant transcriptome analysis. Such integrated analyses can further the holistic understanding of edaphic stress, plant ecotype adaptation and ecosystem function $[23,24]$.

Traditionally, microbial genome alignment is used to remove contaminating non-plant transcripts for a plant-centered analysis, but gene expression and function of the host and microbes are increasingly being investigated in tandem [25]. However, this typically involves the study of model plants in controlled interactions with specific fungi, to facilitate alignment of reads to published genomes for assignment of plant versus microbiome transcripts [26-32]. Studies of more complex, ecologically relevant and genetically diverse non-model plant-microbiome functional interactions are lacking. This current investigation addresses this gap in our knowledge. Using a meta-transcriptomics approach, we have analysed distinct genotypes of Holcus lanatus (L.) selected from two widely contrasting edaphic environments.

The wild grass $H$. lanatus colonizes a wide range of soils with strongly contrasting abiotic stresses including acid bogs, calcareous soils, saline soils and metal(loid)contaminated mine spoils [33]. Such an adaptive range implies selection for different ecotypes, involving genetic changes under differential selection pressures [34, 35], and genetic changes associated with edaphic stress adaptation and plasticity have been observed in this species [36-38]. H. lanatus forms fungal associations [33], some of which facilitate survival and adaptation to edaphic stress [39]. Just as $H$. lanatus exhibits ecotypic variation between different environments [37], so too does its microbiome, including root fungal composition [40]. This most likely facilitates the development of a range of 
beneficial environment-specific plant-microbiome interactions. Because of its inherent plasticity, $H$. lanatus is an ideal species to study plant-microbiome adaptations to edaphic stress, including simultaneous investigation of plant and eukaryotic microbiome responses to variations in soil characteristics influenced by $\mathrm{pH}$, as presented in this study. Extremes of $\mathrm{pH}$ present a wide range of challenges to plants [41], and $H$. lanatus is tolerant of a wide soil $\mathrm{pH}$ range, from at least 3.5 to 8 $[33,34]$. This is exemplified by the populations used in this current study, collected from an acid bog of pH 3.5 (mainly composed of organic material) and a limestone quarry soil of pH 7.5 (calcareous clay, with low level of organic matter content). Biotic factors, particularly soil fungal communities, will contrast in these habitats and will involve beneficial, neutral and detrimental soilspecific plant-microbial interactions [1].

In this study, $10 \mathrm{H}$. lanatus genotypes, 5 acid bog and 5 limestone quarry, were investigated using a full factorial reciprocal soils of origin transplant experiment. The aim was to capture the natural genetic diversity in the host and microbiome via RNA-Seq analysis of root and shoot of this species. Root staining was employed to validate AM and non-AM fungal colonization levels, and shoot elemental content to aid interpretation in the context of nutrient ion homeostasis and edaphic stress response. To our knowledge, no other study to date has investigated the overall functional and taxonomic diversity of ecologically relevant plant root and shoot eukaryotic microbiomes within the ecological context of ecotype plasticity and edaphic stress adaptation.

\section{Methods}

\section{Plants and soils}

Intact $H$. lanatus plants (shoot and root ball) were collected along with topsoil from two locations in Northern Ireland; a disused limestone quarry, pH 7.5, Map. Ref. NR 23472 02816; and an acidic peat bog, pH 3.5, Map. Ref. NW 02918 19660. Plants were collected at least $2 \mathrm{~m}$ apart, ensuring each plant represents a unique genotype of that particular habitat. $H$. lanatus can be propagated from unrooted tillers as roots develop from tiller basal nodes. Unrooted tillers were planted into compost (John Innes no.2) and maintained in a growth chamber (Memmert, Germany) at $20{ }^{\circ} \mathrm{C}, 10000$ LUX light intensity and $12 \mathrm{~h}$ day:night cycle, irrigated to water holding capacity. Therefore, all tillers used in subsequent experimentation originated from under the same conditions.

For the full factorial reciprocal transplant experiment, individual unrooted tillers from 5 acid bog and 5 limestone quarry ecotypes were transplanted onto acid bog and limestone soils, in a fully reciprocal transplantation design. Replication was at genotype level, allowing representation of natural population variation. These soil- grown plants were kept under the same growth chamber conditions as for tiller generation. Treatment coding is as follows: lowercase " $a$ " is for plant ecotype collected from acid bog soil, and "l" from limestone soil. Uppercase " $A$ " indicates acid bog peat as the growth medium, and " $L$ " for limestone soil medium. Plants were harvested after 7 weeks, roots and shoots separated, rinsed in deionized water, frozen in liquid nitrogen and stored at $-80{ }^{\circ} \mathrm{C}$.

\section{Physiochemical analysis of the soils and plants}

Soils were oven dried $\left(70{ }^{\circ} \mathrm{C}\right)$ and milled. Milled soil was compacted into $32-\mathrm{mm}$ cylindrical disks of $\geq 6 \mathrm{~mm}$ width and processed using a Rigaku NEXCG energy dispersive X-ray fluorescence spectrometer (Rigaku, Japan), in the presence of helium, to ascertain elemental content. Inductively coupled plasma-mass spectroscopy (ICP-MS analysis), using an iCAP Qc ICP-MS (ThermoFisher Scientific, USA), was used to compliment XRF analysis, as XRF better quantifies macro-elements and ICP-MS micro-elements. For ICP-MS, dried and milled soils were treated with two acid mixes: $5 \mathrm{ml}$ of $69 \%$ nitric acid or $3 \mathrm{ml} \mathrm{69 \%} \mathrm{nitric} \mathrm{acid} \mathrm{plus} 2 \mathrm{ml} 37 \%$ hydrochloric acid, both acids of Aristar grade. Samples were digested in a Mars6 240/250 microwave (CEM Corporation, USA) at $200{ }^{\circ} \mathrm{C}$ for $30 \mathrm{~min}$ after a one-stage 15 min heating ramp to $165{ }^{\circ} \mathrm{C}$. Element recovery was compared to a soil certified reference material (CRM), NCS ZC73007 and ISE921, (LGC Standards), and the best quantification method for each element, according to CRM recovery, was reported. ICP-MS was also conducted on soil-grown shoot material. Shoots were freeze-dried, milled and digested in a nitric acid and peroxide solution as detailed in Signes-Pastor et al. [42]. Organic matter content was measured via loss of ignition (LoI), quantifying weight loss on controlled burning of soils placed in a porcelain crucible and treated to $24 \mathrm{~h}$ to a temperature of $400{ }^{\circ} \mathrm{C}$ overnight in a muffle furnace. $\mathrm{pH}$ was determined from soil slurries produced from milled soil and distilled water using a $\mathrm{pH}$ probe. Statistical analyses using GLMs were conducted in Minitab13 (Minitab, USA). Where normality tests on residuals indicated non-normality, data was $\log _{2}$ transformed.

\section{Microscopy-based assessment of root fungal colonization}

The reciprocal soil transplantation experiment was repeated using six plants per treatment to assess root colonization rates of AM and non-AM fungi. Additionally, four acid bog and four limestone quarry plants were collected and maintained on their soils of origin to assess natural fungal colonization levels. Roots were cleared in $10 \%$ potassium hydroxide (Sigma-Aldrich), rinsed with 10\% acetic acid (Sigma-Aldrich), stained with a 10\% ink solution (Sheaffer Skrip Black, Sheaffer, USA) 
and mounted in lactoglycerol. The presence and percent colonization of AM and non-AM fungi was assessed based on 100 intersections per plant using the magnified intersection method [43] with an Olympus (Tokyo, Japan) BX43F microscope. Colonization levels were statistically analysed in Minitab using ranked data due to non-normality, employing GLMs and two-sample $t$ tests and plotted using SigmaPlot (SigmaPlot, USA).

\section{RNA extraction and sequencing}

Soil-grown shoots were homogenized to a fine powder under liquid nitrogen and Lysing Matrix D (MP Biomedicals, USA) using two 20-s runs on a Precellys 24-Dual beadbeater (Bertin Technologies, France). Soil-grown roots were pre-ground using $1.5-\mathrm{ml}$ microcentrifuge pestles (Sigma-Aldrich, USA) and $\leq 106-\mu \mathrm{m}$ acid washed glass beads (Sigma-Aldrich) before homogenization using Lysing Matrix A (MP Biomedicals) with the same bead-beater conditions as shoots. RNA was extracted using the RNeasy Plant Mini Kit (QIAGEN, Germany) incorporating on-column DNase treatment (RNase-free DNase Set, QIAGEN) following the standard protocol with the following amendments: $450 \mu \mathrm{l}$ Buffer RLT (containing $4.5 \mu \mathrm{l} \beta$-Mercaptoethanol) was added to the powdered plant material and processed for $5 \mathrm{~s}$ at $5500 \mathrm{rpm}$ in the bead-beater. The lysate was transferred to a QIAshredder spin column and centrifuged for $2 \mathrm{~min}$ at $14000 \mathrm{rpm}$. RNA was double-eluted using the same eluate and stored at $-80{ }^{\circ} \mathrm{C}$.

RNA quality was ascertained using a Nanodrop 8000 spectrophotometer (ThermoFisher Scientific) and an Agilent 2200 Tape Station (Agilent Technologies, USA). Four samples failed quality checks and were not sequenced. Barcoded 125 bp paired-end libraries (Illumina TruSeq, polyA selected to enrich for eukaryotic mRNA and remove rRNA) were generated and sequenced at the Earlham Institute (UK) on an Illumina HiSeq 2500. Samples were sequenced across four lanes (36 samples from the soil transplant experiment plus 3 additional samples; see Additional file 1). The RNA-Seq data (fastq files) is publicly available in ArrayExpress under accession E-MTAB-4014 at https://www.ebi.a c.uk/arrayexpress/E-MTAB-4014.

\section{Quality control of sequencing reads}

Fastq files were quality checked using Fastqc [44] and Illumina adapters removed with seqtk [45]. Reads were trimmed to remove the first 14 bases, those with Phred quality $<20$ from the end of reads, all reads containing any $\mathrm{N}$ bases and those with $<100$ bases post-trimming using Fastq-mcf [46]. Where a read was discarded, its pair was also discarded.
Meta-transcriptome assembly, annotation and alignment Trinity v2.0.6 [47] was used to produce multiple transcriptome assemblies using trimmed paired reads and default settings. Additional plants were added to the transcriptome assembly to increase meta-transcriptome coverage (see Additional file 1). Assembled sequences were sequentially annotated via basic local alignment search tool (BLASTx) [48] using a range of databases and an $e$ value cutoff of $\mathrm{e}-08$. The following databases were downloaded from NCBI reference sequences (RefSeq) [49]: plant-refseq release 71 [50], protozoarefseq release 71 [51] and fungal-refseq release 72 [52]. Brachypodium distachyon and Arabidopsis thaliana databases were downloaded from AgriGO [53]. The following protein databases, including KOG (EuKaryotic Orthologous Group) annotation files for functional annotation, were downloaded from JGI [54, 55]: Arabidopsis lyrata [56], Rhizophagus irregularis [57], Marssonina brunnea [58], Colletotrichum graminicola [59], Agaricus bisporus [60] and Phytophthora soyae [61]. All assembled transcripts were initially BLASTed against plant-refseq, protozoa-refseq, fungi-refseq and the Rhizophagus irregularis protein database, and annotated transcripts were merged with a previously published $H$. lanatus 454 transcriptome assembly [38]. Duplicated annotations were removed based on retention of the transcript with the best BLAST score for each primary accession ID. Transcripts were assigned as plant or non-plant based on best BLAST score. Plant-assigned transcripts were further filtered to remove those with plant-refseq gene identity and sequence coverage $\leq 70 \%$. Microbial-assigned transcripts were further filtered to remove those with best microbial annotation gene identity $\leq 70 \%$ and sequence coverage $\leq 90 \%$. This resulted in a final annotated reference transcriptome containing plant and microbially assigned transcripts. The best microbial annotation was used to obtain kingdom, phylum and species level information for each microbially assigned transcript. BLASTx against various genome protein databases from the JGI (see above), using an $e$ value cutoff of e-08, was subsequently performed, and the most relevant KOG [62] functional annotations for each plant and microbial transcript recorded. Retained plant-assigned transcripts were BLASTed against AgriGO B. distachyon and A. thaliana protein databases to provide identifiers for Gene Ontology (GO)-based enrichment analysis.

Paired reads from the 36 soil-grown samples were aligned to the annotated reference transcriptome using Bowtie2 [63], allowing one mismatch in the seed and reporting on all valid alignments. The number of aligned reads per sample was counted using a Perl script. In order to remove transcripts with 0 or very low counts across most samples, the count table was filtered across 
all 36 samples using edgeR [64] to retain only those transcripts with $\geq 5$ counts in at least 3 out of the 36 samples. Remaining expressed microbial transcripts were further BLASTed against the NCBI non-redundant (nr) protein database [65], using an $e$ value cutoff of e-08, for a further iteration of taxonomic annotation of microbial transcripts based on best BLAST score. Thus, the final taxonomic annotation for all expressed transcripts was taken from the best hit from a combined BLASTx result (NCBI plant-refseq, NCBI protozoa-refseq, NCBI fungi-refseq, JGI Rhizophagus irregularis and NCBI nr).

\section{Statistical and functional analyses}

Differential expression analysis of pair-wise comparisons using the 36 soil-grown samples was conducted using DESeq2 to detect differential expression based on soil type and plant ecotype effects [66]. Separate analysis pipelines were used for identification of differentially expressed plant and microbial transcripts. For differential expression of plant transcripts, one root sample was removed as it showed much lower than average counts for plant-assigned transcripts, and DESeq2 analysis was repeated with 35 samples. Following DESeq2 analysis of plant transcripts, a count of 5 was added to DESeq2 baseMeans for each pair-wise comparison and $\log _{2}$ fold changes $\left(\log _{2} \mathrm{FCs}\right)$ were recalculated to aid removal of significant FC calls from expressed transcripts with low counts. Transcripts were considered significantly differentially expressed if false discovery rate $(F D R)<0.05$ and recalculated absolute $\log _{2} \mathrm{FC} \leq-1$ or $\geq 1$. Significant upregulated and downregulated gene lists were submitted to DAVID using default settings [67] for gene enrichment analysis based on A. thaliana database annotations, to investigate functions and processes involved in the response of $H$. lanatus to extreme soil $\mathrm{pH}$ (Additional files 2, 3, 4, 5, 6, 7, 8 and 9). GO [68] terms outputted from DAVID with a Benjamini-corrected $p$ value $\leq 0.01$ were submitted to REViGO [69] to remove redundant GO terms using default settings. Hierarchical cluster heatmaps were generated using DESeq2 [66] and gplots [70]. A Venn diagram for root and shoot significant genelists was generated using venny [71].

Microbial transcripts showed lower expression levels compared to plant-assigned transcripts, but all samples showed similar numbers of mapped microbialannotated reads. Therefore, all 36 samples were retained for DESeq2 [66] analysis to determine differential gene expression for microbial-annotated transcripts. A clustering heatmap for microbial transcripts was generated in $R$ (hclust and heatmap2). DESeq2 analysis was conducted with addition of 5 to all raw counts to aid estimation of significant $\log _{2} \mathrm{FCs}$ within the generally low count microbial transcriptome data. Microbial transcripts were considered significantly differentially expressed if $\mathrm{FDR}<0.05$, absolute $\log _{2} \mathrm{FC} \leq-1$ or $\geq 1$, and the number of mapped reads crossed a significant expression threshold. This was set as $\geq 5$ mapped reads in at least 3 samples across each of the following 4 treatment types: (a) roots grown on acid bog soil (RA, 8 samples), (b) roots grown on limestone soil (RL, 9 samples), (c) shoots grown in acid bog soil (SA, 10 samples) and (d) shoots grown in limestone soil (SL, 9 samples) to aid identification of treatment effects. This enabled transcripts that passed these thresholds to be deemed as significantly expressed in the RA, RL, SA, SL transcriptome profiles, and was incorporated in response to low microbial read counts. Tables, piecharts and a Venn diagram [71] were subsequently generated to compare the number of significantly expressed transcripts in these four treatment groups. Within each of the four treatment groups (RA, RL, SA, SL), the number of microbial transcripts showing a significant ecotype effect was recorded for various taxonomic designations. Principal component analysis was performed in $\mathrm{R}$ with vegan [72] on expressed root and shoot transcripts of plants and the eukaryotic microbiome. Variance partition analysis was performed in $\mathrm{R}$ with variancePartition [73] on root expressed transcripts of plant, the eukaryotic microbiome and Phialocephala.

\section{Quantitative real-time PCR (qPCR)}

The 19 shoot samples were used for qPCR to verify RNA-Seq gene expression calls using primers for four target genes and primers for 18S [74] as an endogenous control. cDNA and a reverse transcription (RT) control were produced using a QuantiTect Reverse Transcription Kit (QIAGEN), incorporating a DNA removal step. qPCR reactions, no template controls and RT controls, were conducted in triplicate using $10 \mu \mathrm{l}$ PrecisionPlus SYBRgreen Mastermix (Primerdesign, UK), $200 \mathrm{nM}$ per primer and $1 \mu \mathrm{l} \mathrm{cDNA}$ or deionized water in a $20 \mu \mathrm{l}$ reaction. Reactions were conducted using a realplex Mastercycler epgradient S (Eppendorf, Germany), and standard curve data was used to calculate reaction efficiencies for all primer pairs. Melt curves were employed to check for non-specific amplification and contamination. Expression was normalized to $18 \mathrm{~S}$, and statistical analyses were conducted using GLMs and post hoc Tukey tests in Minitab. Where there was nonnormality, $\log _{2}$-transformed data was used. Pair-wise fold changes and standard errors plus $\log _{2} \mathrm{FCs}$ were calculated from the mean normalized expression levels for each treatment, and regressions of RNA-Seq $\log _{2} \mathrm{FC}$ against qRT-PCR $\log _{2} \mathrm{FC}$ were conducted in SigmaPlot 2001. 


\section{Results}

\section{Physiochemical analysis of the soils}

LoI showed the $A$ soil to be primarily organic (LoI 97.2\%) and $L$ soil minerogenic (LoI $5.8 \%$ ) (Additional file 2). The $L$ soil, primarily composed of decomposed substrate, is a clay marl. The organic versus minerogenic nature of these soils is illustrated by their mineral content, where the content of every mineral element was much higher in the mineral versus organic soil, including typical soil markers such as titanium and aluminum (Additional file 2).

\section{Shoot elemental content}

There was greater accumulation of $\mathrm{As}, \mathrm{Cu}, \mathrm{K}$ and $\mathrm{Rb}$, and lower $\mathrm{Ni}$, in $a$ than in $l$ (Table 1). Furthermore, accumulation of $\mathrm{K}$ and $\mathrm{Rb}$ was greater in $a$ than $l$ in both soils, but this was more marked on $A$, as indicated by significant soil and ecotype interaction effects. Accumulation of $\mathrm{P}, \mathrm{Mg}, \mathrm{As}$ and $\mathrm{Rb}$ was significantly greater in plants grown on $A$, compared to $L$.

\section{Meta-transcriptome assembly}

The sequential transcriptome assembly and annotation resulted in 108,335 transcripts, of which 31,098 were annotated as plant and 77,237 as non-plant, to which each sample from the reciprocal transplant experiment aligned. After read alignment and filtering to remove lowly expressed genes, 34,906 transcripts remained, of which 22,487 were assigned as plant and 12,419 as nonplant. Retained non-plant transcripts were re-annotated based on the best score against $\mathrm{nr}$ or fungal/protist databases, resulting in 7716 assigned as fungi, 1141 as protist (Oomycetes) and 2254 as protist (other), while 251 transcripts were re-assigned as nematodes (Additional file 11). Nematode transcripts and those not assigned (1057) to any of these groups were removed from further analyses. For assigned transcripts, KOG annotations were obtained for 16,739 plant, 6813 fungal, 1073 protist (Oomycete) and 2107 protist (other) annotated transcripts (Additional file 3).

\section{Plant gene expression and functional analysis}

The hierarchical cluster heatmap (Fig. 1) and PCoA plot (Fig. 2a) of plant-assigned gene expression showed clear separation of root and shoot samples, with soil type separation evident within root samples, but not in shoots. For shoots and roots, 4 of 5 a grown on $L$ clustered together, indicating a strong consistency of gene expression (Fig. 1). Soil effect $(L, A)$ in roots accounted for $~$ $25 \%$ of gene expression variation, while the plant ecotype effect $(l, a)$ accounted for $\sim 4 \%$ (Fig. $2 b$ ).

Of the 22,487 plant-assigned genes, 6591 were differentially expressed in at least one pairwise comparison, with fewer differentially expressed genes (DEGs) found in shoots (3286 DEGs) (Fig. 3a) than in roots (4037 DEGs) (Fig. 3b), with overlap of 732 DEGs (Fig. 3c). The effect of soil type on differential gene expression was consistently greater than that of plant ecotype, for both shoots (Fig. 3a) and roots (Fig. 3b); a total of 2905 soil effect vs. 781 ecotype effect DEGs were identified in shoots and 3939 soil effect vs. 420 ecotype effect DEGs in roots (Fig. 3). This trend was also reflected in the enriched GO terms obtained for each pairwise comparison in roots and shoots (Additional files 4 and 5).

There were marked differences in soil type response between $a$ and $l$ ecotypes. In shoots, $a$ showed a greater response to soil type than $l$ (2748 vs. 323 DEGs) (Fig. 3a). The opposite was true in roots, where $l$ showed a greater response to soil type compared to a (3009 vs. 2278 DEGs) (Fig. 3b). There were many overlapping soil responses for $a$ and $l$ for roots (1348 DEGs), indicating common root responses to soil type in both ecotypes (Fig. 3b); this was less pronounced in shoots where only 166 DEGs overlapped between $a$ and $l$ (Fig. 3a).

The shoot soil type response for $a$ involved GO terms cell wall and responses to stressors including salt, cadmium, toxic substances, bacteria and wounding (Tables 2 and 3, Additional files 4 and 5). A number of stress response and transport-associated genes were identified as upregulated in a shoots on $A$, compared to $L$, including cation- $\mathrm{H}+$ antiporter $19, \mathrm{~K}$ transporter $16, \mathrm{~K}$ transporter 1 and nitrate transporter 1.5 , with reported function in

Table 1 Shoot mineral contents of reciprocally transplanted H. lanatus shoots as obtained using ICP-MS

\begin{tabular}{|c|c|c|c|c|c|c|c|c|c|c|c|}
\hline \multirow[b]{2}{*}{ Element } & \multicolumn{3}{|l|}{$p$ value } & \multicolumn{4}{|c|}{ Mean content (ppm) } & \multicolumn{4}{|c|}{ Standard error (ppm) } \\
\hline & Soil effect & Ecotype effect & Interaction & $\mathrm{Aa}$ & Al & La & LI & $\mathrm{Aa}$ & Al & La & LI \\
\hline Arsenic & $<0.001$ & $<0.01$ & N.S. & 1.9 & 0.76 & 0.37 & 0.09 & 0.63 & 0.16 & 0.13 & 0.013 \\
\hline Copper & N.S. & $<0.01$ & N.S. & 12 & 9 & 11 & 9 & 0.35 & 0.76 & 1.2 & 0.98 \\
\hline Potassium & N.S. & $<0.01$ & $<0.05$ & 64,000 & 17,000 & 49,000 & 40,000 & 7900 & 11,000 & 4000 & 10,000 \\
\hline Magnesium & $<0.05$ & N.S. & N.S. & 3200 & 2800 & 2700 & 2200 & 290 & 240 & 210 & 7.3 \\
\hline Nickel & 0.137 & $<0.05$ & N.S. & 2.1 & 4.4 & 3.6 & 6.1 & 0.56 & 1.2 & 0.74 & 1.3 \\
\hline Phosphorus & $<0.05$ & N.S. & N.S. & 7400 & 6600 & 2900 & 5000 & 1400 & 760 & 330 & 1200 \\
\hline Rubidium & $<0.001$ & $<0.01$ & $<0.01$ & 42 & 24 & 13 & 12 & 0.82 & 3.4 & 2.1 & 0.98 \\
\hline
\end{tabular}

$A$ acid bog soil, $L$ limestone quarry soil, $a$ acid bog plant ecotype, I limestone quarry plant ecotype 


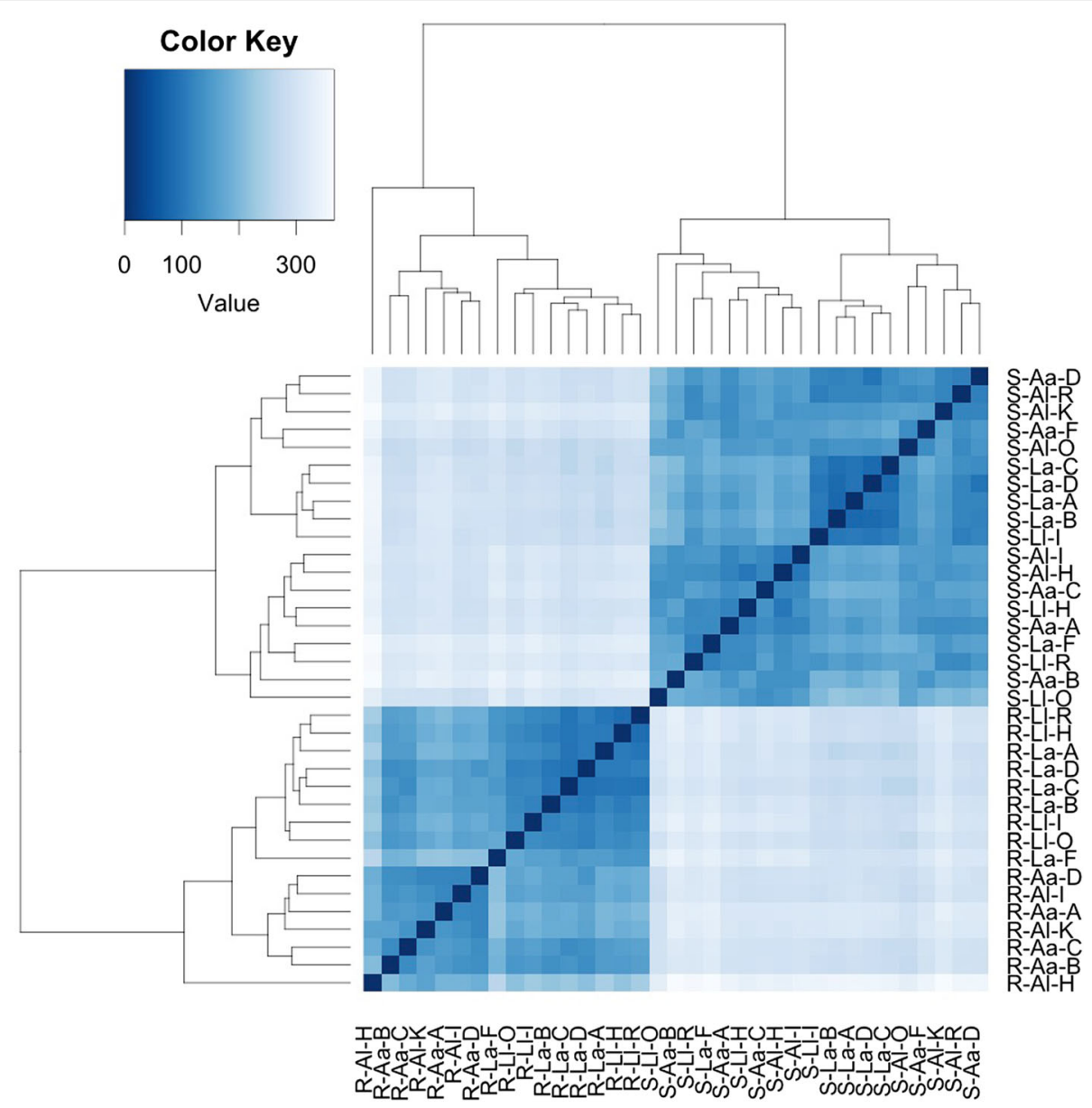

Fig. 1 Hierarchical cluster heatmap of H. lanatus plant-annotated transcripts, generated using normalized gene counts with DESeq2 and gplots in $\mathrm{R}$. The first letter refers to plant ( $\mathrm{S}$ shoot, $\mathrm{R}$ root), the second to soil type ( $A$ acid bog soil, $L$ limestone quarry soil), the third to plant ecotype ( $a$ acid bog plant ecotype, / limestone quarry plant ecotype) and the fourth to the individual plant ID (acid bog plant IDs A, B, C, D, F; limestone quarry plant IDs I, H, R, O, K)

$\mathrm{NO}_{3}^{-}$dependent $\mathrm{K}$ translocation (Additional file 6, references in Additional file 7). Genes GO-annotated as involved in stress response included cinnamate beta-Dglucosyltransferase, involved in phytochelatin production and conversion of xenobiotic substances, and cadmium/ zinc-transporting ATPase HMA1, involved in cation transport, particularly of $\mathrm{Cu}$ (Additional file 6). Also upregulated were genes involved in pathogen defense, including plasma membrane leucine-rich repeat receptor kinase 2 (PEPR2), involved in detecting fungal effectors to initiate plant defenses (Additional file 6). Shoots of $a$ on $A$ compared to $L$ also upregulated a transcript annotated as hydroxycinnamoyl-coenzyme A shikimate, reported to affect lignin composition (Additional file 6). Furthermore, 12-oxophytodienoate reductase 1 and 12oxophytodienoate reductase 7 , genes reported to be involved in jasmonic acid (JA) biosynthesis, were upregulated in $a$ shoots on $A$, compared to $L$ (Additional file 6), with (hemi)biotrophic fungi known to manipulate JA to enable colonization. Response of $l$ shoots to soil was more limited, with fewer DEGs and enriched GO terms. Response to wounding stress was upregulated in $A$ soil, and membrane-associated genes were enriched in $L$ soil (Tables 2 and 3).

Soil type responses identified in $l$ roots included signal transduction, transport, response to stimulus and stress, phosphate starvation and acquisition, lignin production and biosynthesis and oxidation-reduction amongst others (Tables 2 and 3, Additional files 4 and 5). A number of genes involved in lignin biosynthesis and composition, such as laccases 5 and 11 and cinnamyl alcohol dehydrogenase, were upregulated in $l$ roots on $L$, relative to $A$ (Additional file 6). Transport genes upregulated in $l$ on $L$, compared to $A$, were involved in nutrient uptake and transport, particularly for $\mathrm{N}$ and $\mathrm{P}$. These included a range of transporters that facilitate uptake of $\mathrm{N}$ under low $\mathrm{N}$ conditions, such as nitrate transporters 1.1 and 1.5, and high-affinity nitrate transporters 2.1, 2.4, 3.1 

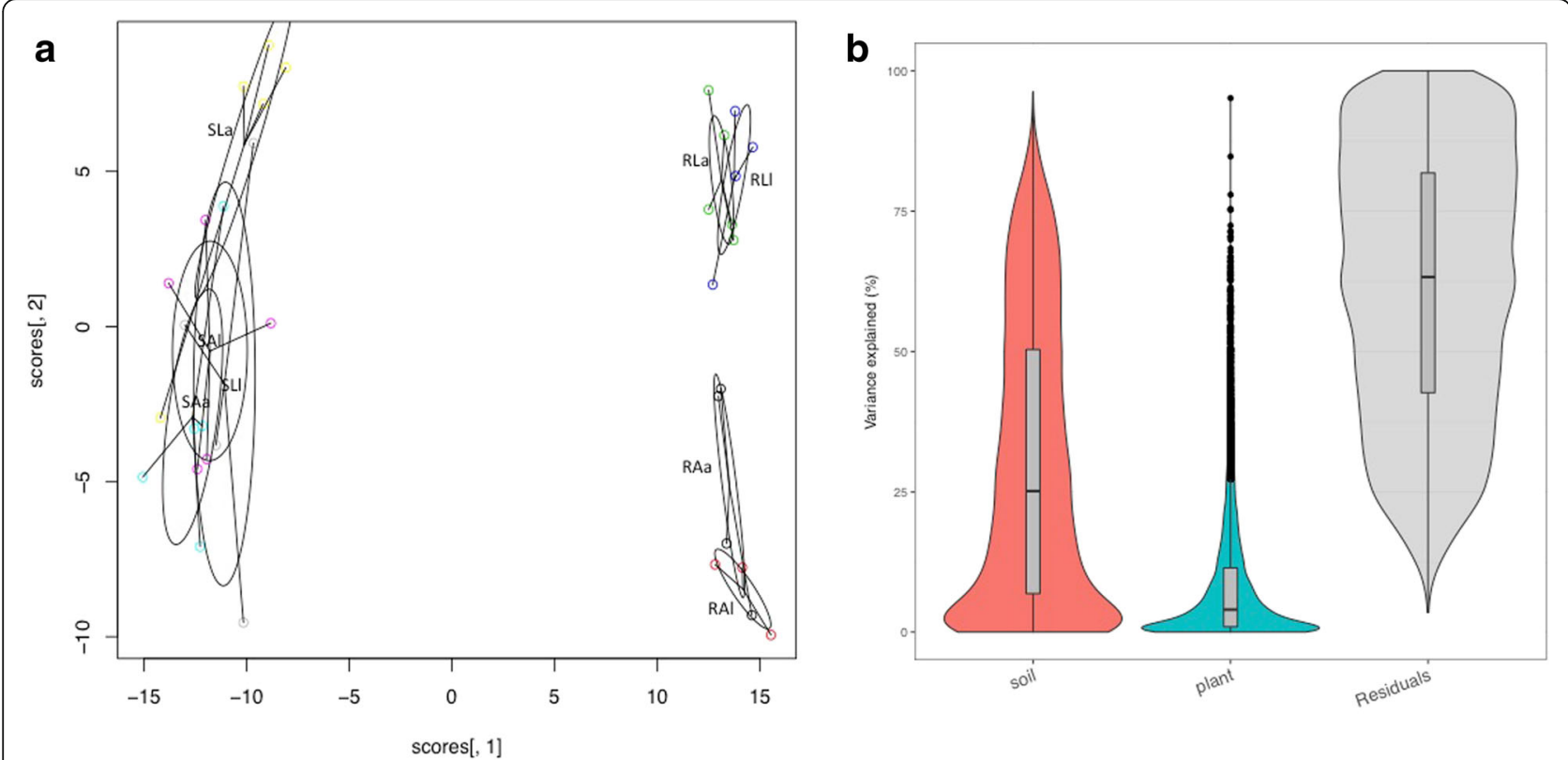

Fig. 2 a PCoA analysis plot of shoot and root H. lanatus plant transcriptome data generated using the vegan package in R. SAa shoot acid bog soil, acid plant; SAI shoot acid bog soil, limestone plant; SLa shoot limestone soil, acid plant; SLI shoot limestone soil, limestone plant. RAa root acid bog soil, acid plant; RAI root acid bog soil, limestone plant; RLa root limestone soil, acid plant; RLI root limestone soil, limestone plant. b Violin plot showing the contributions of soil type, plant ecotype and residuals to variation in the plant root gene expression data. Generated using the variancePartition package in $\mathrm{R}$

and 3.2 (Additional file 6). Nitrate transporter 1.1 is a dual-affinity nitrate transporter thought to be involved in multiple phases of nitrate uptake. With regards to Passimilation, genes upregulated in $l$ roots on $L$, compared to $A$, included purple acid phosphatases, which hydrolyse phosphomonoesters to release $\mathrm{P}$ and are implicated in phosphate use efficiency, as well as highaffinity $\mathrm{K}$ transporters, including $\mathrm{K}$ transporters PT1-11 and PT1-13, known to be important for AM symbiosis (Additional file 6). Also upregulated in $l$ on $L$ were genes involved in $\mathrm{Fe}$ uptake, including phytosiderophorechelated Fe. The latter included iron-phytosiderophore transporter YSL15 (Additional file 6). A number of genes involved in amelioration of oxidative stress were upregulated in $l$ on $L$ compared to $A$, including numerous class III plant peroxidases, including peroxidases 1 and 70 (Additional file 6). The former is reported as a central component in the reactive oxygen gene network response, facilitating amelioration of oxidative stress, with the latter regulated by plant hormones JA and salicylic acid (SAc) in response to pathogen elicitors. Other pathogen defense genes were also upregulated in $l$ on $L$, compared to $A$, including isoflavone reductase and premnaspirodiene oxygenase (Additional file 6). With respect to $\mathrm{K}$ transport and homeostasis, $\mathrm{K}$ channel AKT2 and cation $\left./ \mathrm{H}^{+}\right)$antiporter 15 were upregulated in $l$ roots on $L$, while $\mathrm{K}$ transporter 18 and cation transporter HKT8 were upregulated on $A$ (Additional file 6).
Far fewer genes were upregulated in $l$ on $A$ compared to $L$, but those that were included some catalases and class III plant peroxidases, including peroxidase 70 , plus the aforementioned genes involved in $\mathrm{K}$ homeostasis (Additional file 6).

The soil type responses identified in $a$ roots were broadly similar to those observed in $l$ and included transport, response to stimulus and stress, phosphate starvation and acquisition, lignin production and biosynthesis and oxidation-reduction amongst others (Tables 2 and 3, Additional files 4 and 5). As in $l$, lignin biosynthesis-related genes were upregulated in $a$ on $L$ compared to $A$, suggesting a role of lignification in the $L$ environment in both $a$ and $l$. As observed in $l, \mathrm{P}, \mathrm{N}, \mathrm{Fe}$ uptake and within-plant transport genes were upregulated in $a$ on $L$ relative to $A$, including upregulation of the same nitrate transporters as in $l$, excepting nitrate transporter 1.1, and with the addition of nitrate transporter 1.2 and high-affinity nitrate transporter 2.5 , which plays a role in acquisition and remobilization in nitrogen-starved plants (Additional file 6). As in $l$, there was upregulation of genes involved in uptake of phytosiderophore-chelated $\mathrm{Fe}$ on $L$ compared to $A$, including iron-phytosiderophore transporter YSL15 with the addition of metal-nicotianamine transporter YSL12 (Additional file 6). In both ecotypes, $\mathrm{P}$ transport genes were upregulated on $L$ compared to $A$, including $\mathrm{P}$ transporters PT1-11 and PT1-13, with the addition of 


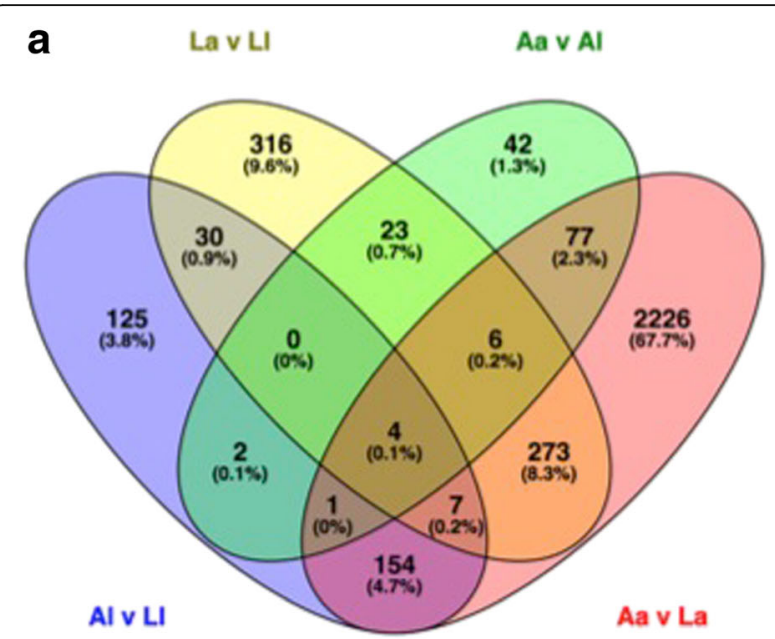

b

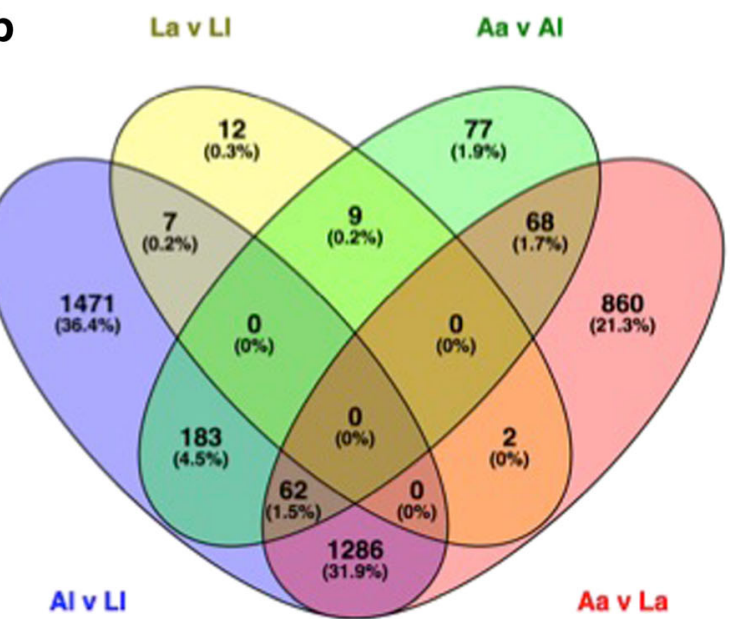

C

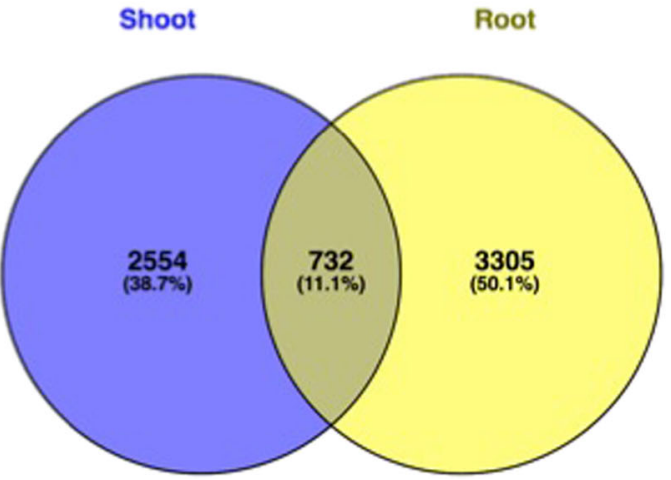

Fig. 3 Venn diagram of significantly differentially expressed Holcus lanatus plant-annotated transcripts. Significance determined as FDR $\leq 0.05$, recalculated absolute $\log _{2} F C \geq 1$ or $\leq-1$, BLAST report $\geq 70 \%$ identity and $\geq 70 \%$ coverage. a Plant transcripts in shoot. b Plant transcripts in root. c Comparison of significantly differentially expressed transcripts obtained for shoots and roots. $L$ limestone quarry soil, $A$ acid bog soil, $a$ acid bog plant ecotype, / limestone quarry plant ecotype; pairwise comparisons La $v$ Ll ecotype effect on limestone soil, Aa v Al ecotype effect in acid bog soil, Al v LI soil effect in limestone plant, Aa $v$ La soil effect in acid plant
PT1-10 and a high-affinity $K$ transporter in $a$ roots (Additional file 6). PT1-10, PT1-11 and PT1-13 are thought to be involved in the establishment of mycorrhizal symbiosis and induced during AM colonization, with PT1-11 implicated in P acquisition via the AM symbiosis. Thus, lignification and increased investment in $\mathrm{P}, \mathrm{N}$ and Fe nutrient acquisition appear to be a response to $L$ in both $H$. lanatus ecotypes, which is reiterated by enrichment of GO terms related to these processes in roots of ecotypes in response to soil type (Table 2).

Other enriched GO terms shared by both roots of both ecotypes in response to soil type related to membrane, cell wall and oxidation-reduction (Table 3). As for $l$, a roots were enriched in pathogen defense-related genes such as isoflavone reductase and premnaspirodiene oxygenase, with the addition of basic endochitinase A on $L$ compared to $A$ (Additional file 6). Regarding genes involved in oxidation-reduction and amelioration of oxidative stress, both $a$ and $l$ roots upregulated a number of class III plant peroxidases in $L$ compared to $A$ (Additional file 6), with production of antioxidant compounds also implicated in $a$. With respect to $\mathrm{K}$ transport and homeostasis genes, both $a$ and $l$ upregulated $\mathrm{K}$ channel AKT2 and cation $/ \mathrm{H}^{+}$antiporter 15 in $L$, and upregulated $K$ transporter 18 and cation transporter HKT8 in $A$. Additionally, $a$ also upregulated $\mathrm{K}$ transporter 5 in $L$ and $\mathrm{K}$ channel KOR2 in $A$ (Additional file 6). As in a shoots, PEPR2, a gene involved in detecting fungal effectors to initiate plant defenses was upregulated in $a$ roots in $A$, compared to $L$. PEPR2 was not upregulated by $l$ shoots or roots in $A$ (Additional file 6).

Although soil type was the overriding effect, there was also an effect of plant ecotype on differential gene expression. This was greater on $L$ than on $A$ in shoots (659 vs. 155 DEGs), in contrast to roots, where ecotype effect was greater on $A$, compared to $L$ (399 vs. 30 DEGs) (Fig. 3). The REViGO enrichment analysis correspondingly showed a larger number of summarized enriched GO terms for ecotype effect on $L$-grown shoots compared to $A$-grown shoots, and in $A$ compared to $L$ grown roots (Table 3, Additional file 5).

Differences in gene expression responses between $a$ and $l$ shoots on $L$ involved membrane, defense response and response to toxins amongst others (Tables 2 and 3, Additional files 4 and 5). Stimulus and stress responserelated genes upregulated on $L$ in $l$ shoots, as compared to $a$, included glutathione $\mathrm{S}$-transferases, a large family with many members involved in detoxification and amelioration of oxidative stress, and pathogen defense genes such as disease resistance protein RPS2 and coronatine-insensitive protein 1 , the latter known to be associated with pathogen defense and JA response (Additional file 6). Shoots of $l$ on $L$ also upregulated 
Table 2 Selected significantly enriched plant-assigned GO terms obtained from DAVID, for various shoot and root pairwise comparisons

\begin{tabular}{lll}
\hline Classification & GO ID & \\
\hline Shoot Aa v La upregulated DEGs & \\
Stress & BP & GO:0009651 \\
& BP & GO:0046686 \\
& BP & GO:0009636 \\
& BP & GO:0009611 \\
& BP & GO:0042742
\end{tabular}

GO description

Response to salt stress
Response to cadmium ion
Response to toxic substance
Response to wounding
Defense response to bacterium

Shoot Aa v La downregulated DEGs

Cell wall

CC

GO:0005618

Cell wall

Response to wounding

Toxin catabolic process

Response to toxic substance

Defense response to bacterium

Response to salt stress

Response to cadmium ion

G0.0046686

$\mathrm{BP}$

GO:0046686

Root Aa v La downregulated DEGs

\begin{tabular}{|c|c|c|c|}
\hline \multirow[t]{2}{*}{ Stress } & $\mathrm{BP}$ & GO:0009651 & Response to salt stress \\
\hline & $\mathrm{BP}$ & GO:0046686 & response to cadmium ion \\
\hline \multirow[t]{5}{*}{ Phosphate } & MF & GO:0003993 & Acid phosphatase activity \\
\hline & BP & GO:0006817 & Phosphate ion transport \\
\hline & MF & GO:0015114 & Phosphate ion transmembrane transporter a \\
\hline & $\mathrm{CC}$ & GO:0009505 & Plant-type cell wall \\
\hline & $\mathrm{BP}$ & GO:0071555 & Cell wall organization \\
\hline Nitrate & $\mathrm{BP}$ & GO:0015706 & Nitrate transport \\
\hline Lignin & $\mathrm{BP}$ & GO:0009809 & Lignin biosynthetic process \\
\hline \multicolumn{4}{|c|}{ Root Al v L/ upregulated DEGs } \\
\hline \multirow[t]{3}{*}{ Stress } & $\mathrm{BP}$ & GO:0009651 & Response to salt stress \\
\hline & $\mathrm{BP}$ & GO:0046686 & Response to cadmium ion \\
\hline & BP & GO:0009636 & Response to toxic substance \\
\hline Cell wall & CC & GO:0005618 & Cell wall \\
\hline \multicolumn{4}{|c|}{ Root Al v L/ downregulated DEGs } \\
\hline \multirow[t]{7}{*}{ Phosphate } & MF & GO:0003993 & Acid phosphatase activity \\
\hline & CC & GO:0009505 & Plant-type cell wall \\
\hline & $\mathrm{BP}$ & GO:0071555 & Cell wall organization \\
\hline & BP & GO:0009834 & Plant-type secondary cell wall biogenesis \\
\hline & $\mathrm{BP}$ & GO:0010411 & Xyloglucan metabolic process \\
\hline & $\mathrm{BP}$ & GO:0045492 & Xylan biosynthetic process \\
\hline & $\mathrm{BP}$ & GO:0045493 & Xylan catabolic process \\
\hline Nitrate & MF & GO:0015112 & Nitrate transmembrane transporter activity \\
\hline \multirow[t]{2}{*}{ Lignin } & BP & GO:0009809 & Lignin biosynthetic process \\
\hline & BP & GO:0046274 & Lignin catabolic process \\
\hline Iron & MF & GO:0020037 & Heme binding \\
\hline
\end{tabular}
$p$ value (Benjamini)

$\begin{array}{ll}1.54 \mathrm{E}-03 & 2.03 \\ 1.67 \mathrm{E}-03 & 2.26 \\ 5.81 \mathrm{E}-06 & 6.15 \\ 3.65 \mathrm{E}-08 & 3.89 \\ 5.51 \mathrm{E}-03 & 229\end{array}$

$1.32 \mathrm{E}-03$ 1.97

$3.71 \mathrm{E}-06$

5.20E-05

13.36

$1.44 \mathrm{E}-03$

8.95

$2.51 \mathrm{E}-03$

Root Aa v La upregulated DEGs

Stress

$\begin{array}{ll}\text { BP } & \text { GO:0009651 } \\ \text { BP } & \text { GO:0046686 }\end{array}$

8.43E-04

2.43

$1.04 \mathrm{E}-04$

9.08E-04

2.17

$1.79 \mathrm{E}-03$

2.30

9.00E-05

6.10

$6.02 \mathrm{E}-03$

7.06

2.07E-03

10.57

$1.48 \mathrm{E}-09$

3.33

4.56E-03

2.28

$7.42 \mathrm{E}-03$

8.34

$1.85 \mathrm{E}-03$

4.56

4.14E-04

2.64

3.73E-06

3.50

9.75E-03

5.88

3.51E-09

3.30

1.10E-03

$1.58 \mathrm{E}-21$

3.97

1.23E-13

3.29

1.59E-04

5.22

1.13E-04

5.47

9.33E-03

5.47

6.73E-04

11.49

8.80E-03

$1.09 \mathrm{E}-07$

5.31

3.95E-04

8.21

5.41E-04 
Table 2 Selected significantly enriched plant-assigned GO terms obtained from DAVID, for various shoot and root pairwise comparisons (Continued)

\begin{tabular}{|c|c|c|c|c|c|}
\hline Classification & $\mathrm{GO} I \mathrm{~L}$ & & GO description & $p$ value (Benjamini) & FE \\
\hline \multicolumn{6}{|c|}{ Root Aa v Al upregulated DEGS } \\
\hline \multirow[t]{2}{*}{ Cell wall } & $\mathrm{BP}$ & GO:0009834 & Plant-type secondary cell wall biogenesis & 4.23E-05 & 19.79 \\
\hline & CC & GO:0009505 & Plant-type cell wall & $2.03 \mathrm{E}-04$ & 4.80 \\
\hline Lignin & $\mathrm{BP}$ & GO:0009809 & Lignin biosynthetic process & $3.79 E-03$ & 11.20 \\
\hline
\end{tabular}

$A=$ acid bog soil, $L=$ limestone quarry soil, $a=$ acid bog plant ecotype, $I=$ limestone quarry plant ecotype. GO categories: $\mathrm{BP}=$ biological process; CC = cellular component; $\mathrm{MF}=$ molecular function. $\mathrm{FE}=$ fold enrichment. The reported $\mathrm{p}$-value is the Benjamini $p$ value, corrected for multiple testing

genes involved in K-uptake and homeostasis and $\mathrm{Na}^{+}$accumulation, in comparison to $a$, in particular, cation- $\mathrm{H}^{+}$ antiporter $19, \mathrm{~K}$ transporter 16 and $\mathrm{K}$ transporter 1 (Additional file 6). Cation- $\mathrm{H}^{+}$antiporter 19 is reported to be associated with $\mathrm{K}$ homeostasis in response to alkaline conditions, and other $\mathrm{K}$ transporters are reported to be involved in salt stress tolerance. In contrast, $\mathrm{K}$ channel KOR2, known to be involved in $\mathrm{K}^{+}$release into xylem sap, was upregulated in $a$ compared to $l$ shoots on $L$ (Additional file 6). Overall, the ecotype effect in shoots on $A$ was less pronounced than on $L$ (Fig. 3a), and was restricted to membrane, signal transduction and port-translational modification-associated genes (Table 3, Additional files 4 and 5).

For roots, significant ecotype responses on $A$ involved the cell wall, lignin biosynthesis and oxidation-reduction related genes amongst others (Tables 2 and 3, Additional files 4 and 5). Lignin biosynthesis and composition genes, such as cinnamyl alcohol dehydrogenase, laccase 4 , laccase 5 and laccase 11, were upregulated in $a$, relative to $l$, suggesting lignin usage in $a$ is related to stressors associated with $A$ soil, which $l$ does not replicate when grown on $A$ (Additional file 6). Roots of $a$ displayed greater expression of a range of class III plant peroxidases compared to $l$ roots in $A$, including peroxidase 1 , central to amelioration of oxidative stress, and peroxidase 70, regulated by JA and SAc, and in response to pathogen elicitors (Additional file 6). Furthermore, $a$ roots had higher expression of K channel AKT2 compared to $l$ roots when grown on $A$ (Additional file 6). This gene is known to be involved in phloem loading and unloading of $\mathrm{K}^{+}$. In contrast to $A$, the ecotype effect in roots on $L$ was much less pronounced (Fig. $3 \mathrm{~b}$ ), involving only 30 genes with no enriched GO terms (Table 3, Additional file 4).

Full DESeq2 results and database annotations for plant annotated transcripts are shown in Additional file 8 with corresponding sequences in fasta format in Additional file 9 .

\section{RNA-Seq gene expression verification using qPCR}

The reliability of the RNA-Seq data and differential expression calls was investigated using qPCR, with genes chosen to cover a range of gene expression patterns between treatments. The $\mathrm{qPCR}$ results verified the RNA-Seq data well, with regressions of $\mathrm{qPCR}$ mean treatment $\log _{2} \mathrm{FC}$ against the mean recalculated RNASeq counterparts showing an $R^{2}$ of $98.2 \%$. Furthermore, where the RNA-Seq indicated a significant difference in gene expression levels between two treatments (FDR $<0.05$ and recalculated $\log _{2} \mathrm{FC} \leq-1$ or $\left.\geq 1\right)$, the qPCR results corroborated this $\left(p<0.05, \log _{2} \mathrm{FC} \leq-1\right.$ or $\left.\geq 1\right)$ (Additional file 10). Primers used for qPCR are shown in Additional file 10.

\section{Microbial gene expression and functional analysis}

Transcripts best annotated as eukaryotic microbes were successfully assembled and functionally annotated (Additional file 3). Fungal and protist transcripts corresponding to all four KOG groups (cellular process and signalling, information storage and processing, metabolism, poorly characterized) were obtained, with the fungal transcriptome dominated by Ascomycetes and the protist transcriptome by Oomycete-annotated genes (Additional files 3 and 12).

Fungal and protist transcripts were detected as significantly expressed in roots and shoots of H. lanatus grown on both $A$ and $L$ (Table 4, Fig. 4). Transcripts demonstrated a root vs. shoot effect on gene expression, as well as strong soil effects on gene expression in roots, with some evidence of a soil effect also identifiable in shoots (Figs. 5 and 6a, b). More transcripts were detected in roots than shoots, and in both, more were detected in plants grown on $A$ than $L$ (Table 4, Fig. 6a). Soil is accounting for more variation in root microbiome gene expression than plant ecotype, but plant ecotype also explains some of the variation (Fig. 7a).

Fungal-annotated transcripts were more prevalent than protist-annotated transcripts in roots and shoots on both soils, with most detected fungal transcripts best annotated as non-AM fungi and mostly assigned to the Ascomycota (Table 4, Fig. 4). Furthermore, greater numbers of Ascomycete-annotated genes were significantly expressed in roots than shoots, but in both, more were detected in plants grown on $A$ than $L$ (Table 4). Ascomycota-annotated genes significantly expressed in 
Table 3 Summarized overview of enriched GO terms based on complete REViGO simplification results, following DAVID GO analysis, for all shoot and root pairwise comparisons

\begin{tabular}{|c|c|c|c|c|c|c|c|c|c|}
\hline & \multirow{2}{*}{$\begin{array}{l}\text { Classification, based on REViGO } \\
\text { output, using similarity }=0.7\end{array}$} & \multicolumn{4}{|l|}{ Shoot } & \multicolumn{4}{|l|}{ Root } \\
\hline & & Aa v La & $A / \vee L I$ & Aa $\vee A l$ & $L a \vee L I$ & Aa v La & Al $\vee L I$ & $A a \vee A l$ & La $\vee L I$ \\
\hline \multirow[t]{17}{*}{ Upregulated DEGs } & Membrane & $x$ & & $x$ & $x$ & $x$ & $x$ & $x$ & \\
\hline & Cell wall & & & & & $x$ & $x$ & $x$ & \\
\hline & Binding & $x$ & & & & & & & \\
\hline & Signal transduction & $x$ & & $x$ & & & & & \\
\hline & Transport & $x$ & & & & & & & \\
\hline & Post-translational modification & $x$ & & $x$ & & & & & \\
\hline & DNA replication/gene expression & & & & & & $x$ & & \\
\hline & Response to stimulus and stress & $x$ & $x$ & & & $x$ & $x$ & & \\
\hline & Phosphate starvation and acquisition & & & & & & & & \\
\hline & Lignin production and biosynthesis & & & & & & & $x$ & \\
\hline & Oxidation-reduction/anti-oxidation & $x$ & & & & & & $x$ & \\
\hline & Cell division and growth & & & & & & & & \\
\hline & Microtubule motor/assembly & & & & & & $x$ & & \\
\hline & Glutathione & $x$ & & & & & & & \\
\hline & Hormones & $x$ & & & & & $x$ & & \\
\hline & Epigenetics & & & & & & & & \\
\hline & Cellulose production & & & & & & & & \\
\hline \multirow[t]{17}{*}{ Downregulated DEGs } & Membrane & $x$ & $x$ & & $x$ & $x$ & $x$ & $x$ & \\
\hline & Cell wall & $x$ & & & & $x$ & $x$ & & \\
\hline & Binding & $x$ & & & $x$ & $x$ & $x$ & & \\
\hline & Signal transduction & $x$ & & & $x$ & & $x$ & & \\
\hline & Transport & & & & $x$ & $x$ & $x$ & & \\
\hline & Post-translational modification & & & & $x$ & & & & \\
\hline & DNA replication/gene expression & $x$ & & & & & & & \\
\hline & Response to stimulus and stress & & & & $x$ & $x$ & & & \\
\hline & Phosphate starvation and acquisition & & & & & $x$ & $x$ & & \\
\hline & Lignin production and biosynthesis & & & & & $x$ & $x$ & & \\
\hline & Oxidation-reduction/anti-oxidation & & & & & $x$ & $x$ & & \\
\hline & Cell division and growth & $x$ & & & & & & & \\
\hline & Microtubule motor/assembly & $x$ & & & & $x$ & $x$ & $x$ & \\
\hline & Glutathione & & & & $x$ & & & & \\
\hline & Hormones & & & & & & & & \\
\hline & Epigenetics & $x$ & & & & & & & \\
\hline & Cellulose production & & & & & $x$ & $x$ & & \\
\hline
\end{tabular}

$A$ acid bog soil, $L$ limestone quarry soil, $a$ acid bog plant ecotype, $/$ limestone quarry plant ecotype

roots grown on $A$ were dominated by the genus Phialocephala, with many of these showing upregulation in $a$, compared to $l$ roots (Table 4, Fig. 4b). In contrast, there was no single dominant Ascomycete genus significantly expressed in roots or shoots on $L$, although Colletotrichum-annotated transcripts were most numerous in roots and Fusarium-annotated transcripts in shoots (Table 4, Fig. 4). These genera, plus others including Acremonium and Trichoderma showed higher expression levels in roots of $l$ compared to $a$, in both soils, particularly $L$ (Table 4 ).

While most non-AM-assembled transcripts were annotated as Ascomycota, transcripts identified as other fungal phyla including Basidiomycota, Chytridiomycota, Cryptomycota and Zygomycota were identified, with greater prevalence in roots compared to shoots (Table 4, 
Table 4 The number of significantly expressed microbial transcripts in root and shoot for each soil

\begin{tabular}{|c|c|c|c|c|c|c|c|c|c|c|c|c|}
\hline & \multicolumn{3}{|c|}{$\begin{array}{l}\text { SA expressed at } \geq 5 \text { reads } \\
\text { in } 3 \text { out of } 10 \text { samples }\end{array}$} & \multicolumn{3}{|c|}{$\begin{array}{l}S L \text { expressed at } \geq 5 \text { reads } \\
\text { in } 3 \text { out of } 9 \text { samples }\end{array}$} & \multicolumn{3}{|c|}{$\begin{array}{l}R A \text { expressed at } \geq 5 \text { reads } \\
\text { in } 3 \text { out of } 8 \text { samples }\end{array}$} & \multicolumn{3}{|c|}{$\begin{array}{l}R L \text { expressed at } \geq 5 \text { reads } \\
\text { in } 3 \text { out of } 9 \text { samples }\end{array}$} \\
\hline & \multirow[t]{2}{*}{ All } & \multicolumn{2}{|c|}{ Plant effect } & \multirow[t]{2}{*}{ All } & \multicolumn{2}{|c|}{ Plant effect } & \multirow[t]{2}{*}{ All } & \multicolumn{2}{|c|}{ Plant effect } & \multirow[t]{2}{*}{ All } & \multicolumn{2}{|c|}{ Plant effect } \\
\hline & & Up in $a$ & up in 1 & & Up in $a$ & Up in I & & Up in $a$ & Up in I & & Up in a & Up in 1 \\
\hline Protists (Oomycetes) & 7 & 0 & 0 & 7 & 0 & 0 & 490 & 8 & 365 & 239 & 0 & 12 \\
\hline Protists (other) & 49 & 0 & 0 & 50 & 0 & 0 & 1183 & 68 & 443 & 1254 & 19 & 80 \\
\hline Ascomycetes & 437 & 0 & 0 & 95 & 2 & 4 & 3646 & 421 & 166 & 2804 & 20 & 1139 \\
\hline Basidiomycetes & 19 & 0 & 0 & 17 & 0 & 0 & 309 & 8 & 62 & 139 & 1 & 6 \\
\hline Glomeromycotina & 1 & 0 & 0 & 1 & 0 & 0 & 12 & 1 & 2 & 122 & 0 & 1 \\
\hline Fungi (other) & 4 & 0 & 0 & 3 & 0 & 0 & 108 & 5 & 31 & 188 & 0 & 10 \\
\hline \multicolumn{13}{|l|}{ Ascomycota (selected) } \\
\hline Phialocephala & 3 & 0 & 0 & 0 & 0 & 0 & 1886 & 289 & 3 & 21 & 0 & 4 \\
\hline Colletotrichum & 22 & 0 & 0 & 2 & 0 & 0 & 63 & 2 & 8 & 166 & 2 & 65 \\
\hline Fusarium & 76 & 0 & 0 & 9 & 0 & 3 & 105 & 1 & 24 & 104 & 0 & 25 \\
\hline Acremonium & 66 & 0 & 0 & 6 & 0 & 0 & 47 & 1 & 10 & 39 & 0 & 11 \\
\hline Trichoderma & 31 & 0 & 0 & 7 & 0 & 0 & 58 & 5 & 8 & 66 & 0 & 22 \\
\hline
\end{tabular}

The number of significantly expressed microbial transcripts (All) is defined as the number of transcripts that obtained $\geq 5$ aligned reads in at least three samples from each of the following treatments: root acid bog soil (RA), root lime-stone soil (RL), shoot acid bog soil (SA) and shoot lime-stone soil (SL). Significant ecotype effects (absolute $\log _{2} F C \leq-1$ or $\geq 1, F D R<0.05$ ) as identified by DESeq2 analysis are reported in subsequent columns for each treatment group under the heading plant effect

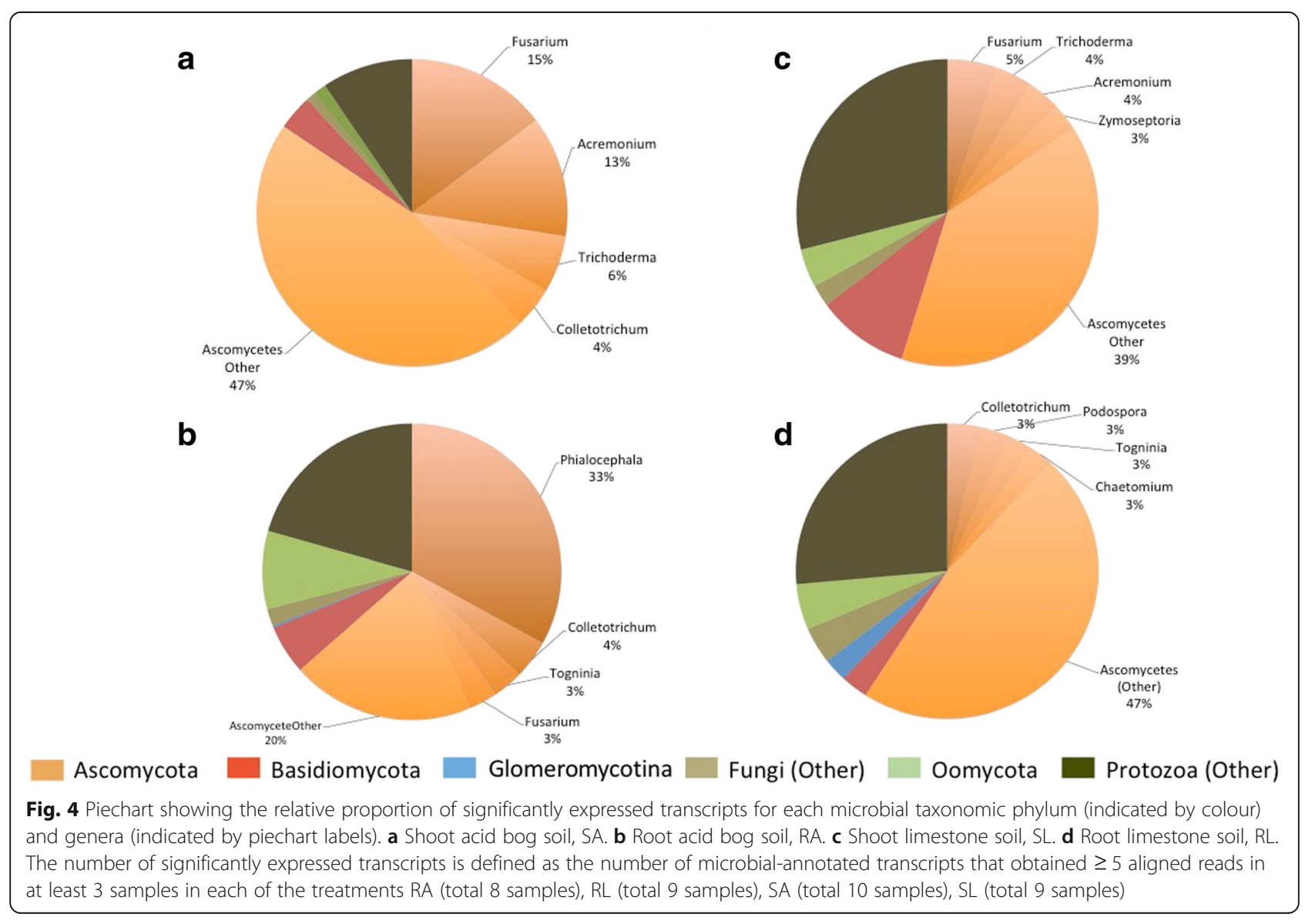




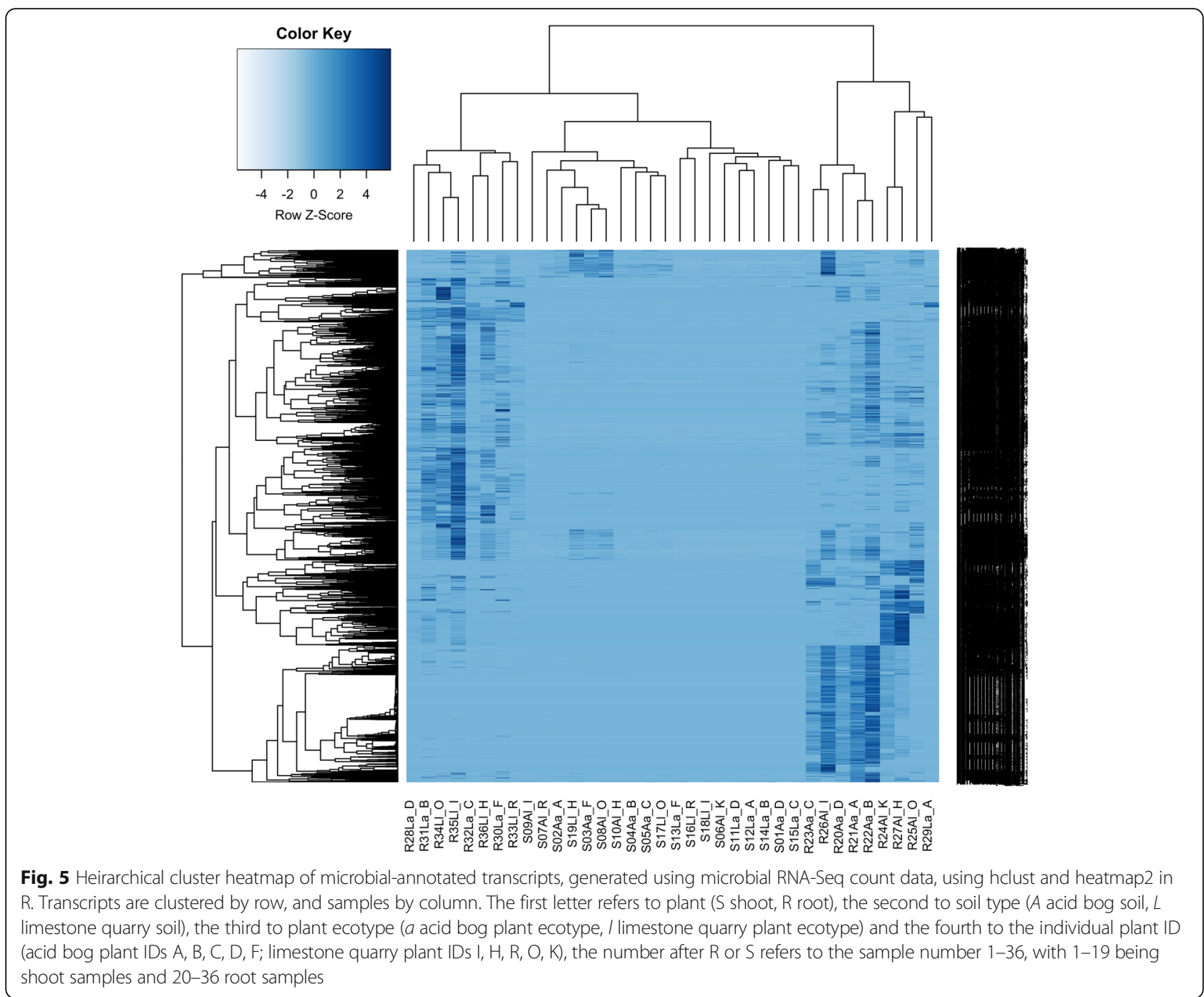

Fig. 4, Additional file 12). Basidiomycetes showed greater activity from $A$-grown roots than $L$, and within $A$, more Basidiomycete-annotated transcripts were upregulated in $l$ roots than $a$ (Table 4). Basidiomycete-annotated transcripts upregulated in $l$ roots compared to $a$ roots in $A$ soil were predominantly annotated as KOG translation and energy production (Additional file 13).

Most Ascomycota transcripts significantly expressed at a level of $\geq 5$ counts in $\geq 3$ samples in roots from $A$ were KOG annotated as involved in metabolism, including energy production and conversion and transport and metabolism of carbohydrates, amino acids and lipids (Table 5). Roots from $L$ were mainly KOG annotated as information storage and processing, particularly translation, ribosomal structure and biogenesis. This was also the case for shoots from $A$ and $L$, although transcripts KOG annotated as metabolism were also well represented in shoots from $A$, and cellular processes and signalling in shoots from $L$. In all categories, fewer
Ascomycota transcripts were annotated in shoots, due to lower overall transcript detection compared to roots (Tables 4 and 5).

Other Ascomycota-annotated KOGs of interest included intracellular trafficking, inorganic ion transport and metabolism, signal transduction mechanisms and replication and recombination and repair. Some of these are putatively involved in fungal virulence and infectivity, with others likely to be involved in nutrient acquisition, uptake and homeostasis, likely with functions related to stresses associated with $A$ or $L$. For roots grown on $A$, many significantly expressed transcripts annotated with these KOG functions and putative uses were also annotated as Phialocephala (Additional file 11, references in Additional file 7). A total of $225 A$-grown root Phialocephala genes were upregulated in $a$ compared to $l$, with 24 of these KOG annotated as amino acid transport and metabolism (Table 6), including arginase, involved in amino acid breakdown to release $\mathrm{N}$ 

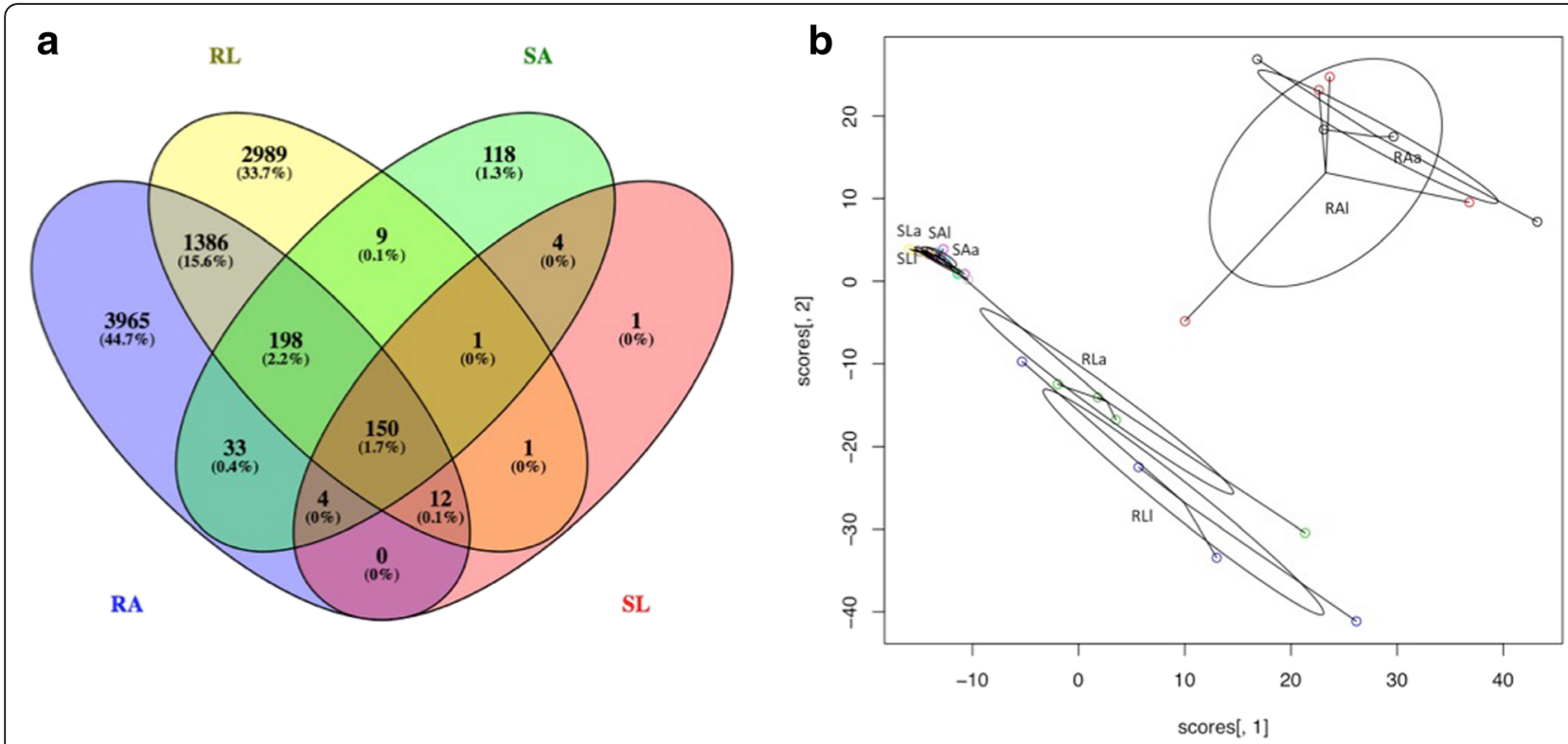

Fig. 6 a Venn diagram of significantly expressed transcripts in root and shoot in each soil; root acid bog soil (RA), root limestone soil (RL), shoot acid bog soil (SA) and shoot limestone soil (SL). The number of significantly expressed transcripts is defined as the number of microbial-annotated transcripts that obtained $\geq 5$ aligned reads in at least 3 samples in each of the treatments RA (total 8 samples), RL (total 9 samples), SA (total 10 samples), SL (total 9 samples). b PCoA analysis plot of the shoot and root microbial data generated using the vegan package in R. SAa shoot acid bog soil, acid plant; SAI shoot acid bog soil, limestone plant; SLa shoot limestone soil, acid plant; SLI shoot limestone soil, limestone plant. RAa root acid bog soil, acid plant; RAI root acid bog soil, limestone plant; RLa root limestone soil, acid plant; RLI root limestone soil, limestone plant

(Additional file 11). Phialocephala-annotated genes involved in metal(loid) homeostasis, $\mathrm{P}$ transport, and stress tolerance were more numerous in roots grown on $A$ compared to $L$ (Additional file 11). Furthermore, a number of these transcripts were upregulated in roots of $a$, compared to $l$, on $A$, including a $\mathrm{Zn}$ transporter, inorganic $\mathrm{P}$ transporters, a $\mathrm{K}^{+} / \mathrm{H}^{+}$-antiporter and aldehyde dehydrogenases, with many of the latter upregulated in both ecotype roots when grown on $A$ compared to $L$; aldehyde dehydrogenases are associated with energy
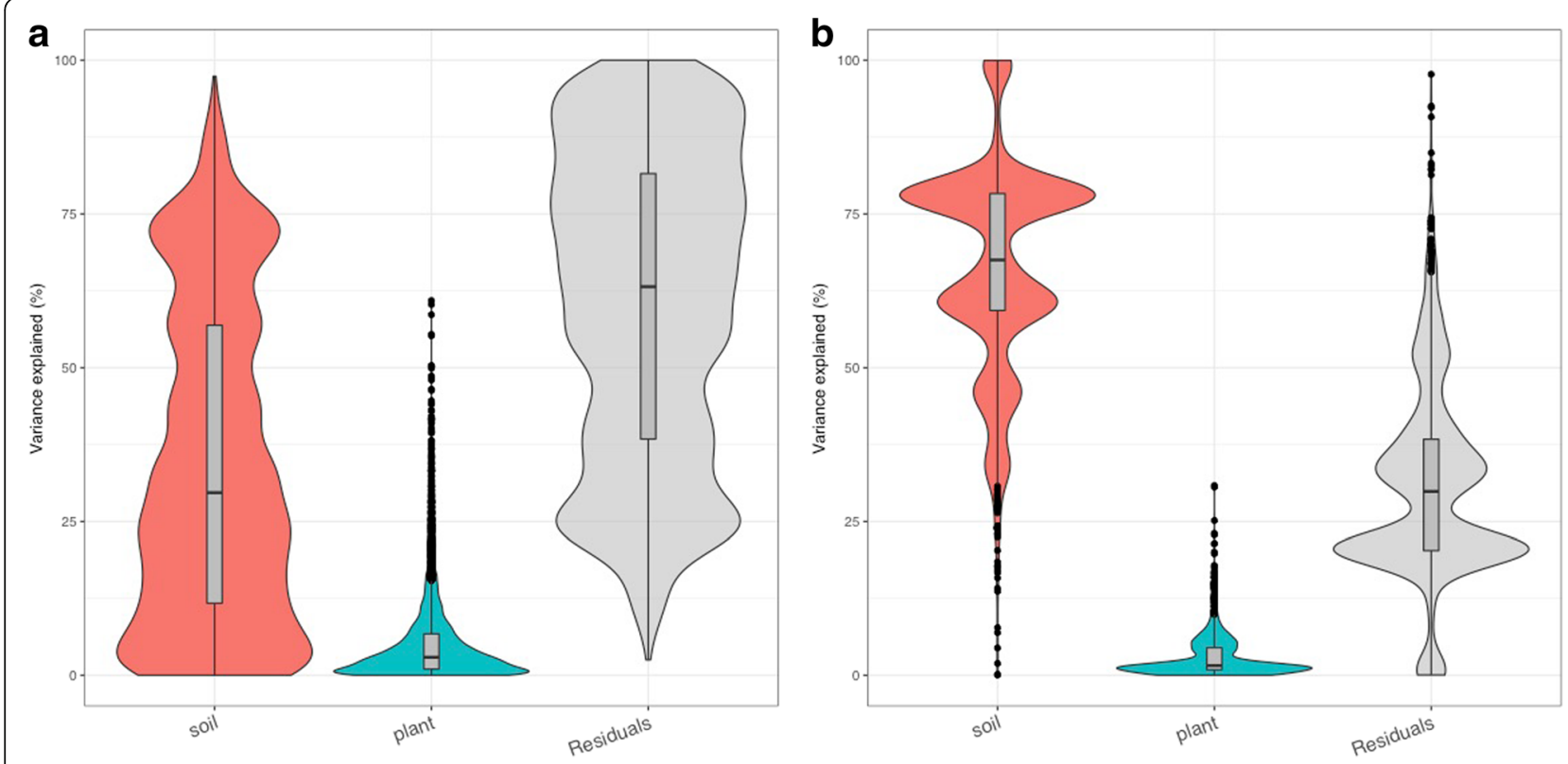

Fig. 7 Violin plot showing the contributions of soil type, plant ecotype and residuals to variation in gene expression data of a all root eukaryotic microbiota and $\mathbf{b}$ root Phialocephala expressed transcripts. Generated using the variancePartition package in R 
Table 5 Significantly expressed KOG-annotated Ascomycota transcripts in root and shoot in each soil

\begin{tabular}{|c|c|c|c|c|c|c|c|c|c|c|c|c|}
\hline \multirow{3}{*}{ Ascomycetes } & \multicolumn{3}{|c|}{$\begin{array}{l}\text { SA expressed at } \geq 5 \\
\text { reads in } 3 \text { out of } 10 \\
\text { samples }\end{array}$} & \multicolumn{3}{|c|}{$\begin{array}{l}\text { SL expressed at } \\
\geq 5 \text { reads in } 3 \\
\text { out of } 9 \text { samples }\end{array}$} & \multicolumn{3}{|c|}{$\begin{array}{l}R A \text { expressed at } \geq 5 \\
\text { reads in } 3 \text { out of } \\
8 \text { samples }\end{array}$} & \multicolumn{3}{|c|}{$\begin{array}{l}R L \text { expressed at } \geq 5 \\
\text { reads in } 3 \text { out of } \\
9 \text { samples }\end{array}$} \\
\hline & \multirow[t]{2}{*}{ All } & \multicolumn{2}{|c|}{ Plant effect } & \multirow[t]{2}{*}{ All } & \multicolumn{2}{|c|}{ Plant effect } & \multirow[t]{2}{*}{ All } & \multicolumn{2}{|c|}{ Plant effect } & \multirow[t]{2}{*}{ All } & \multicolumn{2}{|c|}{ Plant effect } \\
\hline & & Up in a & Up in I & & Up in $a$ & Up in 1 & & Up in a & Up in 1 & & Up in a & Up in I \\
\hline Cellular processes and signaling & 71 & 0 & 0 & 28 & 2 & 0 & 769 & 89 & 30 & 729 & 6 & 274 \\
\hline Cell motility & 0 & 0 & 0 & 0 & 0 & 0 & 1 & 0 & 0 & 0 & 0 & 0 \\
\hline Cell wall/membrane/envelope biogenesis & 1 & 0 & 0 & 0 & 0 & 0 & 36 & 2 & 0 & 45 & 0 & 21 \\
\hline Cytoskeleton & 7 & 0 & 0 & 7 & 2 & 0 & 96 & 13 & 7 & 74 & 1 & 19 \\
\hline Defense mechanisms & 2 & 0 & 0 & 0 & 0 & 0 & 13 & 0 & 0 & 8 & 0 & 1 \\
\hline Extracellular structures & 4 & 0 & 0 & 0 & 0 & 0 & 5 & 0 & 0 & 3 & 0 & 0 \\
\hline $\begin{array}{l}\text { Intracellular trafficking, secretion, } \\
\text { and vesicular transport }\end{array}$ & 0 & 0 & 0 & 2 & 0 & 0 & 114 & 15 & 3 & 77 & 0 & 28 \\
\hline Nuclear structure & 0 & 0 & 0 & 0 & 0 & 0 & 9 & 1 & 0 & 7 & 0 & 4 \\
\hline $\begin{array}{l}\text { Posttranslational modification, protein turnover, } \\
\text { chaperones }\end{array}$ & 50 & 0 & 0 & 17 & 0 & 0 & 334 & 30 & 14 & 355 & 3 & 128 \\
\hline Signal transduction mechanisms & 7 & 0 & 0 & 2 & 0 & 0 & 161 & 28 & 6 & 160 & 2 & 73 \\
\hline Information storage and processing & 137 & 0 & 0 & 35 & 0 & 0 & 918 & 51 & 57 & 785 & 4 & 348 \\
\hline Chromatin structure and dynamics & 7 & 0 & 0 & 4 & 0 & 0 & 40 & 2 & 2 & 35 & 0 & 22 \\
\hline Replication, recombination and repair & 1 & 0 & 0 & 0 & 0 & 0 & 46 & 1 & 0 & 1 & 0 & 0 \\
\hline RNA processing and modification & 1 & 0 & 0 & 0 & 0 & 0 & 128 & 13 & 2 & 34 & 1 & 14 \\
\hline Transcription & 3 & 0 & 0 & 31 & 0 & 0 & 90 & 8 & 2 & 61 & 0 & 28 \\
\hline Translation, ribosomal structure and biogenesis & 125 & 0 & 0 & 0 & 0 & 0 & 614 & 27 & 51 & 654 & 3 & 284 \\
\hline Metabolism & 134 & 0 & 0 & 16 & 0 & 4 & 1083 & 113 & 50 & 763 & 3 & 319 \\
\hline Amino acid transport and metabolism & 10 & 0 & 0 & 0 & 0 & 0 & 149 & 26 & 1 & 97 & 0 & 45 \\
\hline Carbohydrate transport and metabolism & 16 & 0 & 0 & 4 & 0 & 0 & 179 & 32 & 7 & 162 & 2 & 91 \\
\hline $\begin{array}{l}\text { Cell cycle control, cell division, chromosome } \\
\text { partitioning }\end{array}$ & 0 & 0 & 0 & 0 & 0 & 0 & 77 & 3 & 1 & 42 & 0 & 17 \\
\hline Coenzyme transport and metabolism & 1 & 0 & 0 & 1 & 0 & 0 & 38 & 1 & 2 & 27 & 0 & 4 \\
\hline Energy production and conversion & 65 & 0 & 0 & 8 & 0 & 4 & 309 & 19 & 35 & 267 & 0 & 88 \\
\hline Inorganic ion transport and metabolism & 13 & 0 & 0 & 0 & 0 & 0 & 66 & 8 & 0 & 61 & 0 & 23 \\
\hline Lipid transport and metabolism & 11 & 0 & 0 & 1 & 0 & 0 & 125 & 12 & 0 & 51 & 0 & 26 \\
\hline Nucleotide transport and metabolism & 1 & 0 & 0 & 0 & 0 & 0 & 42 & 2 & 0 & 20 & 0 & 9 \\
\hline $\begin{array}{l}\text { Secondary metabolites biosynthesis, } \\
\text { transport and catabolism }\end{array}$ & 17 & 0 & 0 & 2 & 0 & 0 & 98 & 10 & 4 & 36 & 1 & 16 \\
\hline Poorly characterized & 31 & 0 & 0 & 1 & 0 & 0 & 434 & 67 & 8 & 253 & 0 & 96 \\
\hline Function unknown & 2 & 0 & 0 & 0 & 0 & 0 & 85 & 6 & 0 & 13 & 0 & 4 \\
\hline General function prediction only & 29 & 0 & 0 & 1 & 0 & 0 & 349 & 61 & 8 & 240 & 0 & 92 \\
\hline Total KOG annotated, expressed & 373 & 0 & 0 & 80 & 2 & 3 & 3204 & 320 & 145 & 2528 & 13 & 1037 \\
\hline
\end{tabular}

The number of significantly expressed KOG-annotated Ascomycota transcripts (All) is defined as the number of transcripts that obtained $\geq 5$ aligned reads in at least 3 samples from each of the following treatments: root acid bog soil (RA), root limestone soil (RL), shoot acid bog soil (SA) and shoot limestone soil (SL). Significant ecotype effects (absolute $\log _{2} \mathrm{FC} \leq-1$ or $\geq 1, \mathrm{FDR}<0.05$ ) as identified by DESeq2 analysis are reported in subsequent columns for each treatment group under the heading plant effect

production and oxidative stress tolerance. Transcripts annotated as these were also expressed by Ascomycete genera other than Phialocephala on both soils, with a significant number of transcripts in $l$ roots showing increased expression compared to $a$ in both soils (Additional file 11). A greater number of Ascomycota genes involved in stress tolerance and repair were detected in $A$ than $L$, including those involved in oxidative stress response and DNA damage detection and repair, many of which were best annotated as Phialocephala. Fungal virulence and infectivity related genes, particularly casein kinases, transport protein Sec61 and GTP- 
Table 6 Significantly expressed KOG annotated Phialocephala transcripts in root and shoot in each soil

\begin{tabular}{|c|c|c|c|c|c|c|c|c|c|c|c|c|}
\hline \multirow{3}{*}{ Phialocephala } & \multicolumn{3}{|c|}{$\begin{array}{l}\text { SA expressed at } \geq 5 \\
\text { reads in } 3 \text { out of } \\
10 \text { samples }\end{array}$} & \multicolumn{3}{|c|}{$\begin{array}{l}S L \text { expressed at } \geq 5 \\
\text { reads in } 3 \text { out of } \\
9 \text { samples }\end{array}$} & \multicolumn{3}{|c|}{$\begin{array}{l}R A \text { expressed at } \geq 5 \\
\text { reads in } 3 \text { out of } \\
8 \text { samples }\end{array}$} & \multicolumn{3}{|c|}{$\begin{array}{l}R L \text { expressed at } \geq 5 \\
\text { reads in } 3 \text { out of } \\
9 \text { samples }\end{array}$} \\
\hline & \multirow[t]{2}{*}{ All } & \multicolumn{2}{|c|}{ Plant effect } & \multirow[t]{2}{*}{ All } & \multicolumn{2}{|c|}{ Plant effect } & \multirow[t]{2}{*}{ All } & \multicolumn{2}{|c|}{ Plant effect } & \multirow[t]{2}{*}{ All } & \multicolumn{2}{|c|}{ Plant effect } \\
\hline & & Up in a & Up in 1 & & Up in a & Up in I & & Up in $a$ & Up in I & & Up in a & Up in 1 \\
\hline Cellular processes and signaling & 1 & 0 & 0 & 0 & 0 & 0 & 370 & 61 & 0 & 6 & 0 & 2 \\
\hline Cell motility & 0 & 0 & 0 & 0 & 0 & 0 & 1 & 0 & 0 & 0 & 0 & 0 \\
\hline Cell wall/membrane/envelope biogenesis & 0 & 0 & 0 & 0 & 0 & 0 & 23 & 1 & 0 & 0 & 0 & 0 \\
\hline Cytoskeleton & 0 & 0 & 0 & 0 & 0 & 0 & 37 & 6 & 0 & 0 & 0 & 0 \\
\hline Defense mechanisms & 0 & 0 & 0 & 0 & 0 & 0 & 10 & 0 & 0 & 0 & 0 & 0 \\
\hline Extracellular structures & 0 & 0 & 0 & 0 & 0 & 0 & 5 & 0 & 0 & 0 & 0 & 0 \\
\hline $\begin{array}{l}\text { Intracellular trafficking, secretion, } \\
\text { and vesicular transport }\end{array}$ & 0 & 0 & 0 & 0 & 0 & 0 & 73 & 14 & 0 & 1 & 0 & 0 \\
\hline Nuclear structure & 0 & 0 & 0 & 0 & 0 & 0 & 6 & 1 & 0 & 0 & 0 & 0 \\
\hline $\begin{array}{l}\text { Posttranslational modification, } \\
\text { protein turnover, chaperones }\end{array}$ & 1 & 0 & 0 & 0 & 0 & 0 & 114 & 18 & 0 & 5 & 0 & 2 \\
\hline Signal transduction mechanisms & 0 & 0 & 0 & 0 & 0 & 0 & 101 & 21 & 0 & 0 & 0 & 0 \\
\hline Information storage and processing & 1 & 0 & 0 & 0 & 0 & 0 & 322 & 35 & 0 & 8 & 0 & 2 \\
\hline Chromatin structure and dynamics & 0 & 0 & 0 & 0 & 0 & 0 & 18 & 1 & 0 & 0 & 0 & 0 \\
\hline Replication, recombination and repair & 0 & 0 & 0 & 0 & 0 & 0 & 43 & 1 & 0 & 0 & 0 & 0 \\
\hline RNA processing and modification & 0 & 0 & 0 & 0 & 0 & 0 & 86 & 10 & 0 & 0 & 0 & 0 \\
\hline Transcription & 0 & 0 & 0 & 0 & 0 & 0 & 64 & 7 & 0 & 0 & 0 & 0 \\
\hline Translation, ribosomal structure and biogenesis & 1 & 0 & 0 & 0 & 0 & 0 & 111 & 16 & 0 & 8 & 0 & 2 \\
\hline Metabolism & 1 & 0 & 0 & 0 & 0 & 0 & 601 & 81 & 2 & 4 & 0 & 0 \\
\hline Amino acid transport and metabolism & 0 & 0 & 0 & 0 & 0 & 0 & 117 & 24 & 0 & 1 & 0 & 0 \\
\hline Carbohydrate transport and metabolism & 0 & 0 & 0 & 0 & 0 & 0 & 91 & 19 & 0 & 0 & 0 & 0 \\
\hline $\begin{array}{l}\text { Cell cycle control, cell division, } \\
\text { chromosome partitioning }\end{array}$ & 0 & 0 & 0 & 0 & 0 & 0 & 46 & 2 & 0 & 0 & 0 & 0 \\
\hline Coenzyme transport and metabolism & 0 & 0 & 0 & 0 & 0 & 0 & 25 & 1 & 0 & 0 & 0 & 0 \\
\hline Energy production and conversion & 1 & 0 & 0 & 0 & 0 & 0 & 93 & 11 & 1 & 1 & 0 & 0 \\
\hline Inorganic ion transport and metabolism & 0 & 0 & 0 & 0 & 0 & 0 & 38 & 7 & 0 & 0 & 0 & 0 \\
\hline Lipid transport and metabolism & 0 & 0 & 0 & 0 & 0 & 0 & 85 & 6 & 0 & 0 & 0 & 0 \\
\hline Nucleotide transport and metabolism & 0 & 0 & 0 & 0 & 0 & 0 & 33 & 2 & 0 & 1 & 0 & 0 \\
\hline $\begin{array}{l}\text { Secondary metabolites biosynthesis, } \\
\text { transport and catabolism }\end{array}$ & 0 & 0 & 0 & 0 & 0 & 0 & 73 & 9 & 1 & 1 & 0 & 0 \\
\hline Poorly characterized & 0 & 0 & 0 & 0 & 0 & 0 & 319 & 48 & 1 & 0 & 0 & 1 \\
\hline Function unknown & 0 & 0 & 0 & 0 & 0 & 0 & 78 & 5 & 0 & 0 & 0 & 0 \\
\hline General function prediction only & 0 & 0 & 0 & 0 & 0 & 0 & 241 & 43 & 1 & 0 & 0 & 1 \\
\hline Total KOG annotated & 3 & 0 & 0 & 0 & 0 & 0 & 1612 & 225 & 3 & 18 & 0 & 5 \\
\hline
\end{tabular}

The number of significantly expressed KOG-annotated Phialocephala transcripts (All) is defined as the number of transcripts that obtained $\geq 5$ aligned reads in at least 3 samples from each of the following treatments: root acid bog soil (RA), root limestone soil (RL), shoot acid bog soil (SA) and shoot limestone soil (SL). Significant ecotype effects (absolute $\log _{2} \mathrm{FC} \leq-1$ or $\geq 1, \mathrm{FDR}<0.05$ ) as identified by DESeq2 analysis are reported in subsequent columns for each treatment group under the heading plant effect

binding ADP-ribosylation factor Arf1, were expressed in both $A$ and $L$ and annotated by a range of Ascomycete genera. Many of these, particularly those annotated as Phialocephala, were more strongly expressed in $A$ (Additional file 11). Casein kinases are known to be essential for cell integrity and fungal virulence and Arf1 may be involved in fungal morphogenesis and virulence. Roots grown on $L$ showed a greater number of Ascomycota-annotated ferric reductases, known to be involved in $\mathrm{Fe}$ acquisition than those on $A$. Of these, 
eight genes, including two annotated as Colletotrichum, were upregulated in roots of $l$, compared to $a$, on $L$ (Additional file 11). Ascomycete-annotated genes from a range of genera proposed to be involved in fungal $\mathrm{K}$ homeostasis were detected in both soils, with a Phialocephala-annotated $\mathrm{K}^{+} / \mathrm{H}^{+}$-antiporter and $\mathrm{Na}^{+} / \mathrm{K}^{+}$transporter showing greater expression on $A$, while those upregulated in $L$ roots were annotated with a range of other Ascomycota genera, including a Colletotrichum-annotated $\mathrm{K}^{+} / \mathrm{H}^{+}$-antiporter. $\mathrm{K}^{+} / \mathrm{H}^{+}$-antiporters influence the plasma membrane potential of fungi, thereby increasing $\mathrm{pH}$ tolerance.

In roots on $A, 1612$ of 3204 significantly expressed genes with Ascomycete KOG annotations were annotated as Phialocephala, in contrast to roots on $L$, where only 18 of 2530 were annotated as Phialocephala (Tables 5 and 6). No expression of Phialocephala-annotated genes was identified in shoots on $L$, and only 3 Phialocephala-annotated genes were shown to be expressed in shoots on $A$, highlighting this organism as a root endophyte characteristic of $A$ (Table 6). Accordingly, due to stronger expression on $A$, soil accounts for most of the Phialocephala expression variance, further to that a small proportion is explained by plant ecotype (Fig. 7b). Coupled with the greater gene expression of Phialocephala-annotated transcripts in roots of $a$, compared to the $l$, when grown on $A$, this presents the hypothesis that $H$. lanatus plants native to $A$ have plantmicrobiome interaction adaptations to $A$. This adaptation involves a close association with an Ascomycete of the genus Phialocephala, or closely related to Phialocephala, perhaps with various roles in $\mathrm{P}$ and $\mathrm{N}$ acquisition, cation transport, metal(loid) tolerance and stress and pathogen resistance for this soil.

For roots on $L, 166$ significantly expressed genes were annotated as Colletotrichum, 65 of which were upregulated in $l$, compared to $a$ (Table 4). This compares with only 63 significantly expressed genes annotated as Colletotrichum expressed in roots on $A$, few of which show an ecotype-specific effect on $A$ (Table 4). Again, this could point to ecotype-specific plant-microbiome interactions with Colletotrichum or related organisms on $L$ adapted $H$. lanatus plants, with the interaction perhaps having a beneficial role in aiding Fe acquisition in $L$.

A total of 144 transcripts best annotated as Glomeromycotina with KOG annotations were assembled and expressed (Additional file 3), with 108 of these significantly expressed in roots on $L$, and only 11 in $A$ (Additional file 14). Furthermore, there was little difference in root Glomeromycotina expression due to plant ecotype in either soil (Table 4, Additional file 14), indicating greater AM fungal activity in $L$, compared to $A$ roots in both ecotypes. As expected, no significant expression of Glomeromycotina-annotated genes was observed in shoots (Table 4, Additional file 14, Fig. 4).
Of the 108 Glomeromycotina KOG-annotated transcripts significantly expressed in $L, 43$ were annotated as involved in cellular process and signalling (posttranslational modification, signal transduction), 22 in information storage and processing (translation), 38 in metabolism (amino acid, carbohydrate, lipid, secondary metabolite, inorganic ion transport, energy production), and 5 annotated as poorly characterized (Additional file 14). These included 3 ferric reductases, which may be involved in $\mathrm{Fe}$ acquisition (Additional file 11). Of the 11 Glomeromycotina KOG-annotated transcripts shown to be significantly expressed on $A$, 4 were KOG annotated as cellular processing and signalling, 6 as information storage and processing and 1 as metabolism (Additional file 14). Overall, the number of transcripts identified as expressed by Glomeromycotina was lower than expected, possibly due to there being only one AM fungal genome for annotation of AM fungal transcripts, making it likely that a number of AM fungal expressed transcripts, in particular those AM more distantly related to $R$. irregularis, were missed during the iterative annotation procedure.

Protist-annotated transcripts were assembled and KOG annotated, with 1073 of these assigned as Oomycete and 2107 as protists (other) (Additional file 3). Detection of transcripts best annotated as protists (other) and protists (Oomycete) was greater in roots than in shoots, with Oomycetes making up 29\% of all root expressed protists on $A$, and $\sim 16 \%$ on $L$, indicating that Oomycetes were more active in roots on $A$ (Fig. 4, Table 4, Additional file 12). More protist-annotated genes were upregulated in roots in $l$, compared to $a$, on both soils (Table 4). This was most pronounced on $A$, with 365 out of 490 root expressed Oomycete-annotated transcripts upregulated in $l$ compared to $a$, while in $L$ only 12 out of 239 significantly expressed Oomyceteannotated transcripts were upregulated in $l$ compared to $a$ (Table 4, Additional file 12). A similar trend could be observed for protists (other) annotated transcripts where 443 out of 1183 significantly root expressed transcripts in $A$ were upregulated in $l$, compared to $a$, and 80 out of 1254 on $L$ (Table 4, Additional file 12). Of the 365 Oomycete-annotated transcripts upregulated in $l$ roots compared to $a$ roots in $A$ soil 119 were KOG annotated with cellular process and signalling, 108 with information storage and processing and 88 with metabolism. Most of these genes were associated with transcription and translation-type processes (49 of these annotated with post-translational modification, 51 with signal transduction, 23 with RNA processing, 17 with transcription, 62 with translation)) (Additional file 12).

Full DESeq2 results and database annotations for microbial-annotated transcripts are shown in Additional file 12 with corresponding sequences in fasta format in Additional file 15. 


\section{Fungal colonization rates assessed using microscopy}

Roots of all plants were colonized with both AM and nonAM fungi, whether grown in the reciprocal transplant experiment on $A$ or $L$ (Fig. 8a, c, Additional file 16) or maintained on their soils of origin (Fig. 8b, d). Hyphal colonization by AM fungi was significantly greater in roots on $L$ than $A$ in plants maintained on their soil of origin (Fig. 8b) (two-sample $t$ test, $t=-4.9, \mathrm{df}=5, p<0.01$ ), as well as in plants grown on $L$ in the reciprocal transplant experiment (Fig. 8a, Additional file 16) (post hoc Tukey test, $p<0.001$ following ANOVA, $\left.F_{(1,21)}=65.51, p<0.001\right)$. In contrast, hyphal colonization with non-AM fungi was significantly greater in roots from $A$ than $L$ in plants kept on their soils of origin (Fig. 8b) (two-sample $t$ test, $t=4.38$, $\mathrm{df}=6, p<0.01$ ), as well as in plants grown on $A$ in the reciprocal transplant experiment (Fig. 8a, Additional file 16) (post hoc Tukey test, $p<0.001$ following ANOVA, $F_{(1,20)}$ $=72.66, p<0.001)$. Furthermore, in the reciprocal transplant experiment, $l$ showed significantly greater non-AM fungal hyphal colonization compared to $a$ when grown on $A$ (two-sample $t$ test, $t=-2.54, \mathrm{df}=8, p<0.05$ ) (Fig. 8a). This is corroborated by a significant interaction effect between soil type and plant ecotype (ANOVA, $F_{(1,20)}=6.06$, $p<0.05)$, which indicated that the difference in non-AM hyphal colonization between soil types is greater in $l$ than in $a$ (Additional file 16). In the transplant experiment, vesicles were only detected in roots grown on $L$ (Fig. 8c, Additional file 16). In contrast, arbuscules were detected in roots grown on both soils, with significantly more detected in roots grown on $L$ than $A$ (ANOVA, $F_{(1,21)}=37.05, p$ $<0.001$; post hoc Tukey test, $p<0.001$ ) (Fig. 8c, Additional file 16). Images of AM and non-AM fungal structures identified in stained $H$. lanatus roots from the reciprocal transplant experiment can be seen in Additional file 17.

\section{Discussion}

In this study, the response of $H$. lanatus ecotypes adapted to acid bog or and limestone quarry soil was characterized via meta-transcriptome analysis, complemented by chemical and root staining characterization, to evaluate plant and associated eukaryotic microbiota responses to edaphic stress. The approach is novel, as it assesses natural, multi-species colonization, in distinct genotypes of two disparate $H$. lanatus ecotypes, in a reciprocal transplant experiment. This provides insights into edaphic, ecotypic and ecotype-microbiome interaction effects. While RNA-Seq-based analysis of eukaryotic microbiome taxonomies is subject to some limitations, due to the conserved nature of protein coding sequences, and the limited number of fully genomesequenced fungal and protist species [25], it has the advantage that it can capture information on the active, functional aspects of the microbiome. Incorporation of host and microbiome responses is crucial to understanding plant survival in harsh environments as host-microbe interactions contribute to plant survival, providing symbiont-mediated nutrient acquisition and protection against metal(loid) toxicity and pathogens [75, 76].

The iterative annotation strategy employed, using high-quality protein databases in the absence of a $H$. lanatus genome, enabled successful taxonomic and functional assignment of plant and microbe de novo assembled transcripts, based on the closest related organisms present in the database. This enabled us to perform a meta-transcriptome-based gene expression analysis to quantify plant and eukaryotic microbiome responses to extremes of soil, as they differ across the $\mathrm{pH}$ range from acid bog to calcareous limestone soil. This approach proved successful in identifying significant soil and ecotype effects, with respect to $H$. lanatus root and shoot expressed transcripts. It also provided a means to assess the activity of specific fungal subgroups and Oomycota in H. lanatus roots and shoots in each soil. Furthermore, it incorporated insights into microbial community composition, but unlike DNA-based amplicon sequencing, it measured fungal and protist microbiome activity in root and shoot rather than presence/absence. Additionally, the approach demonstrated proposed functional redundancy within the microbial community, as demonstrated by the expression of particular genes by multiple genera, such as aldehyde dehydrogenases and ferric reductases.

Plants can utilize a variety of adaptive measures to tolerate the stresses associated with acidic and alkaline soils $[1,34]$, and the plant gene expression results suggest that $H$. lanatus is employing nutrient acquisition and defense strategies in response to $A$ and $L$. These observed differences are in line with the differences in nutrient availability and dominant $\mathrm{N}$ and $\mathrm{P}$ sources for the soils studied. Ammonium is the dominant $\mathrm{N}$ source in acid bog soils, and phosphate is fixed by Fe [1]. Calcareous soils are typically poor sources of Fe and P, with phosphate fixed by $\mathrm{Ca}$, and $\mathrm{N}$ typically in nitrate form [1], and both ecotypes upregulated genes involved in P, Fe and high-affinity nitrate acquisition on $L$ soil. In contrast, $\mathrm{P}$ and cation transporters $(\mathrm{Cd}, \mathrm{Zn}, \mathrm{Cu}, \mathrm{K}, \mathrm{H}+)$ involved in amelioration of abiotic stress responses were upregulated in both ecotypes in $A$. Furthermore, elemental analysis showed that shoot $\mathrm{P}, \mathrm{As}$ and $\mathrm{Mg}$ content was higher in $A$ in both ecotypes, with $\mathrm{K}$ contents greater in $a$ than in $l$, particularly in $A$ soil. This corresponded with upregulation of a range of $\mathrm{K}$ transporters and homeostasis genes in shoots and roots of $a$ on $A$ compared to $L$ and with upregulation of $\mathrm{K}$ channel AKT2 in $a$ compared to $l$ roots on $A$. AKT2 has been shown to be expressed in root stellar tissue and is reported as key to $\mathrm{K}^{+}$loading and unloading in phloem tissues [77]. This transporter could, therefore, be implicated in the greater 

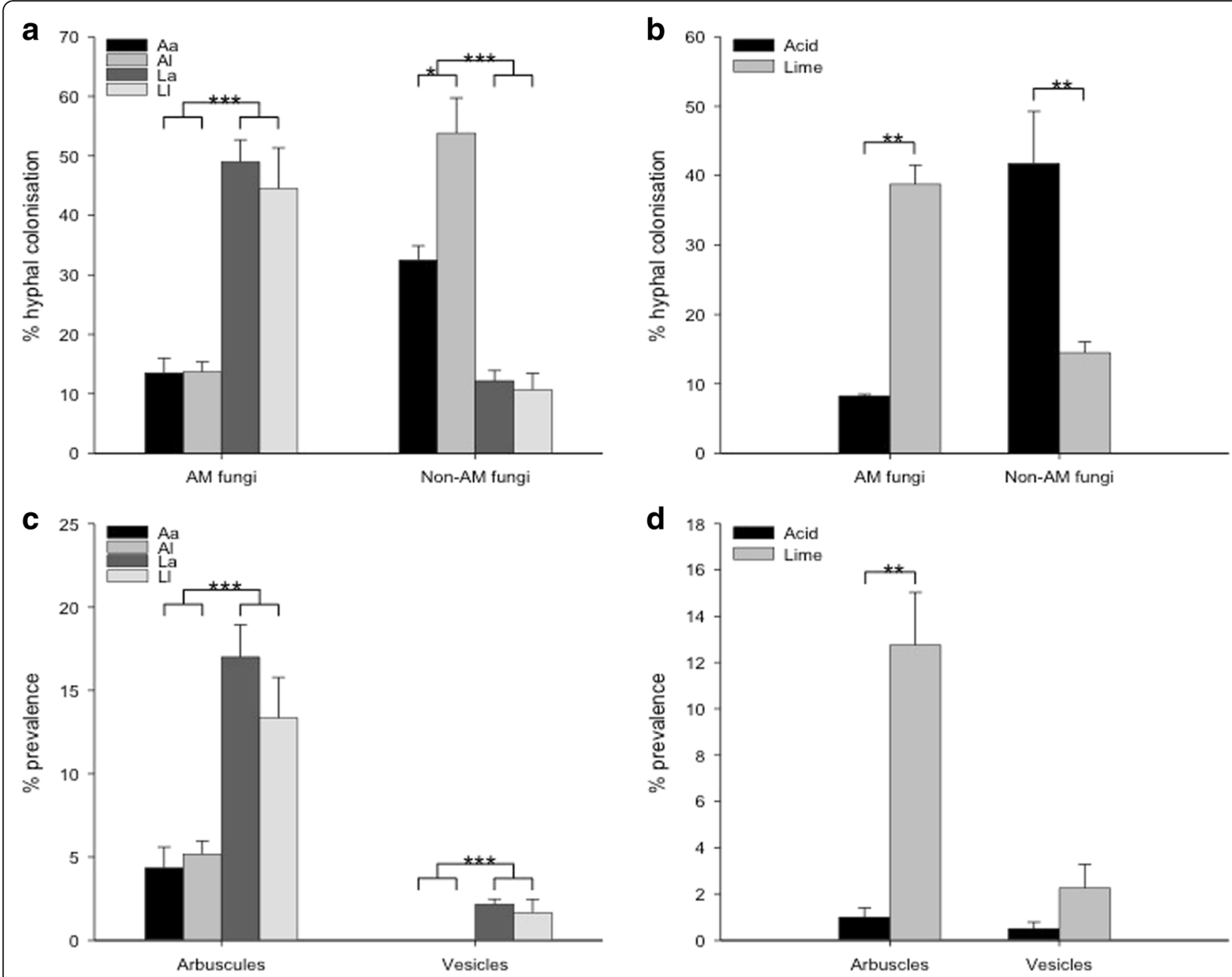

Fig. 8 Microscopy-based assessment of \% colonization of fungal hyphae and structures in roots of H. lanatus grown on limestone quarry and acid bog soil. a Mean AMF and non-AMF hyphal colonization rates in plants grown in a full factorial reciprocal transplantation design. b Mean AMF and non-AMF hyphal colonization rates in plants maintained on their soils of origin, either acid bog or limestone quarry. c Mean arbuscule and vesicle prevalence in plants grown in a full factorial reciprocal transplantation design. $\mathbf{d}$ Mean arbuscule and vesicle prevalence in plants maintained on their soils of origin, either acid bog or limestone quarry. A acid bog soil $L$ limestone quarry soil, a acid bog plant ecotype, / limestone quarry plant ecotype; error bars represent standard error. Significant differences are indicated with asterisks, ${ }^{*} p<0.05,{ }^{* *} p<0.01$ and ${ }^{* * *} p<0.001$

$\mathrm{K}$ content in a compared to $l$ shoots on $A$. Maintenance of $\mathrm{K}$ homeostasis is well recognized as a stress tolerance mechanism in plants, including acid soil-grown plants, and high-affinity $K$ transporters employed under $\mathrm{K}$ starvation have been shown to be regulated by genes responsive to low $\mathrm{pH}$ stress and associated toxicities $[1,78]$. Increased investment into $\mathrm{K}$ homeostasis, and accumulation of $\mathrm{K}$ in shoots, therefore, characterizes acid bog soil adapted $H$. lanatus.

Plants can implement various defensive measures to prevent colonization by pathogenic organisms [79]. Initial plant defense involves recognition of fungal elicitors that trigger plant immune responses to prevent colonization. Elicitor signalling involving receptor-like kinases and pattern recognition receptors (PRRs), including PEPR2 [17], that sense either pathogen- associated molecular patterns (PAMPs) or endogenous damage-induced molecular patterns (DAMPs). The observed upregulation of PEPR2 in roots and shoots of $a$ on $A$ compared to $L$ may, therefore, indicate induction of defensive mechanisms in response to pathogen attack in $a$ on $A$. Furthermore, lignin biosynthesis is involved in plant response to biotic and abiotic stresses, including nutrient stress and prevention of pathogenic colonization $[31,80]$. The stronger expression of lignification genes in both ecotypes on $L$ could be in response to limestone soilspecific stressors, such as low $\mathrm{P}, \mathrm{Fe}$ and $\mathrm{N}$ availability as well as biotic factors [80]. In addition to lignification genes, both ecotypes upregulated other pathogen defenserelated genes, on $L$ compared to $A$. Gene responses affecting the cell wall may have been contributing factors to the observed lower fungal activity in roots on $L$ compared to 
$A$ in both ecotypes. Alternatively, the observed lower fungal activity in $L$ could simply be due to lower presence of these organisms in this soil. Given the role of root lignification in preventing pathogenic infection [31, 80], upregulation of lignin biosynthesis-related genes in $a$ compared to $l$ on $A$, could relate to a greater ability of the $a$, than the $l$, to limit soil and pathogen-induced cell damage and infection on $A$, backed up by the use of defensive genes such as PEPR2 in roots and shoots of $a$ on $A$ compared to $L$. The limestone ecotype, on the other hand, as not adapted to $A$, may be less able to induce this response when grown on this soil type. This hypothesis is based on the observed lower induction of plant genes involved in cell wall lignification, but greater detectable Ascomyctete, Basidiomycete and Oomycete activity in $l$ compared to $a$ roots in $A$. Most of the Oomycete-annotated transcripts were best annotated as Phytophthora and were more active in A compared to L. Phytophthora are major plant pathogens, and cell wall strengthening has previously been proposed as a key method of defense against colonization of these organisms [77], with lignin conferring rigidity to cell walls [80]. Hence, greater expression of lignin biosynthesis-associated genes in $a$ may play a role in limiting fungal and Oomycete pathogenic activity in $a$ compared to $l$ roots, when grown in $A$.

Phialocephala-annotated genes were identified as the dominant fungal genera in root gene expression profiles of both ecotypes in $A$, with this genus near absent in roots in $L$. Root endophytes within this genus have previously been reported $[81,82]$ and can protect against pathogens such as the Oomycete Phytophthora [82] which was more active in $A$ than in $L$. Within roots grown on $A$, many Phialocephala-annotated transcripts were upregulated in $a$ compared to $l$, while the opposite effect was observed for Oomycetes and Basidiomycetes, and some other Ascomycete genera. Whether this is mediated via Phialocephala-induced cell wall strengthening to prevent pathogen infection, as has been observed in Glomeromycotina-induced pathogen resistance [83], is worth investigation; greater Phialocephala expression in $a$ compared to $l$ on $A$ coincided with increased expression of plant lignin-associated genes in $a$ compared to $l$ on $A$.

Colletotrichum-annotated transcripts were more prevalent in $L$-grown roots compared to $A$-grown roots. Within roots from $L$, many Colletotrichum and some other Ascomycete genera (including Fusarium, Acremonium and Trichoderma) annotated transcripts were upregulated in $l$ compared to $a$. The genus Colletotrichum contains mostly pathogenic, but some mutualistic endophytes [84], with symbiotic interactions shown to involve improved P nutrition [85] or production of anti-fungal compounds [86]. It is worth investigating the role of these fungi in plant nutrition and defense in $H$. lanatus roots on limestone quarry soil and whether they contribute to plant nutrition in this low $\mathrm{P}$ availability environment, particularly since some Fusarium species have been identified as endophytes in some plants, including H. lanatus [27, 87].

Just as plants respond to their edaphic environment, so do fungi, initiating nutrient uptake and other stress response measures [75]. Calcareous soils are typically limited in bioavailable $\mathrm{Fe}$ [88], so the greater prevalence of Ascomycota ferric reductases in roots from $L$, could be an adaptation to stresses associated with this soil type. Whether the non-AM fungi then provide Fe to the plant would be worth further investigation. Both non$\mathrm{AM}$ and AM displayed clear soil type effects on colonization and gene expression activity, with greater numbers of significantly expressed Glomeromycotina annotated transcripts and AM hyphae identified in roots grown in $L$ compared to $A$ soil. $H$. lanatus colonization percentages of $25-50 \%$ found here by staining in the $L$ are consistent with other studies [39]. Lower levels of AM colonization in roots from $A(\sim 10 \%)$, plus lower levels of Glomeromycotina activity identified by RNASeq are typical, as AM fungi are less prevalent in highly acidic soil such as the acid bog soil $A$ used here $[5,89]$, with some studies indicating sometimes no presence of AM fungi in highly acidic soil [89]. AM fungi have been shown to occur in a wide variety of soil types ranging from pasture to acid peat, with community composition most strongly influenced by $\mathrm{pH}$, rain and soil type [90]. Both $H$. lanatus ecotypes responded to low $\mathrm{P}$ availability on the $L$ by upregulating genes involved in $\mathrm{P}$ uptake, transport and increased P use efficiency, suggesting this as an adaptation to $L$ in both ecotypes, with low $\mathrm{P}$ also known to stimulate colonization and symbiotic action by AM [91]. With further additions of Glomeromycotina genomes to publicly available databases, metatranscriptome analysis as presented here, will most likely become more effective with respect to the identification of functional responses in AM fungi. That Glomeromycotina were contributing to $\mathrm{P}$ acquisition in both ecotypes in $L$ is displayed by upregulation of genes involved in forming and maintaining the symbiosis, plus genes directly involved in $\mathrm{P}$ acquisition from the interaction. Furthermore, the gene expression profile of Glomeromycotinaannotated transcripts in $L$ suggests a potential role for AM fungi in Fe nutrition, with expression of AM ferric reductases in $L$. Improved plant Fe nutrition, mediated via AM fungi and involving ferric reductases, has previously been reported, with $\mathrm{Fe}$ nutrition of plants particularly positively affected by AM fungi under high $\mathrm{pH}$ conditions, and in more sandy soils [92], and this could, therefore, be an important function of AM fungi in $L$, in addition to improved $\mathrm{P}$ nutrition. In our study, the number of transcripts observed for Glomeromycotina was comparably low, potentially because there is only one publicly available 
sequenced genome for Glomeromycotina [57] and, therefore, transcripts from a range of Glomeromycotina may be missed by the BLASTx-based annotation, and hence not included in the overall meta-transcriptome.

Non-AM fungal colonization has been shown to increase tolerance to enhanced bioavailability of toxic metal(loid)s under acidic soil conditions [11], and here, Phialocephala HMT1 and a considerable number of genes involved in repair and stress tolerance were upregulated in A. Non-AM fungi, including Phialocephala, can also provide nutrition benefits to the host in stressful soils, highly acidic soils and in conditions where $\mathrm{N}$ is predominantly locked up in organic forms [6], via breakdown into available $\mathrm{N}$ sources, i.e. priming $[2,6,81]$. This could be relevant the role of such fungi in plants grown on the acid bog soil, particularly since a number of Phialocephala amino acid transport-associated genes were strongly expressed in $A$, and within this soil more strongly upregulated in $a$ than $l$. In this study, Phialocephala-annotated transcripts upregulated in roots in $A$ included arginase, asparagine and D-aspartate oxidase, with arginase, furthermore, identified as being upregulated in a compared to $l$ in $A$. This is relevant in this context as arginase, asparagine and D-aspartate oxidase have all been shown to play a role in release of $\mathrm{N}$ from organic sources [93-95], and it can be proposed that Phialocephala may, therefore, provide the plant with access to $\mathrm{N}$ from organic sources in $A$. The upregulation of Phialocephala $\mathrm{K}$ homeostasis genes in roots from $A$ compared to $L$, combined with the upregulation of Phialocephala $\mathrm{K}^{+} / \mathrm{H}^{+}$antiporter in $a$ compared to $l$ on $A$, suggests that soil-specific fungi are using $\mathrm{K}$ homeostasis to combat edaphic stress, as was proposed in plants. It is, therefore, proposed that non-AM fungal colonization may benefit $H$. lanatus, with this study pointing in particular to a possible beneficial role of organisms closely related to Phialocephala in A. Although a range of species of Phialocephala are documented as beneficial to plants, the genomes of some species have also been shown to contain elements common to pathogenic or saprotrophic lifestyles [96], with some Phialocephala shown to cause disease in grasses [97]. Furthermore, the nature of plant-fungal interactions are complex $[13,98]$ and can be influenced by soil type, plant ecotype and time, with neutral and symbiotic endophytes potentially turning into saprophytes once seasonally mediated plant senescence sets in [75]. The proposed beneficial endophytic role of Phialocephala in our phenotypically healthy-looking $H$. lanatus plants in acid bog soil is therefore subject to further investigation, and pathogenic activity of these organisms at some point during the lifecycle of the plants cannot be ruled out.

Fungal symbionts are implicated in enhancing plant abiotic stress tolerance and facilitate stress tolerance in plants via habitat-adapted symbiosis [99], with significant three-way interaction effect on cumulative shoot weight (endophyte $\times$ ecotype $\times$ soil) previously reported in Festuca arundinacea [100]. In our full factorial, reciprocal soil transplant investigation, we have shown that, albeit to a lesser degree than soil type, host ecotype can also influence non-AM fungi colonization and activity.

\section{Conclusions}

Fungal and Oomycete activity was higher in roots grown in our organic-rich acid bog soil compared to the minerogenic limestone soil, and low levels of fungal and Oomycete activity were observed in all shoots. Ascomycota showed the highest level of activity in roots grown in both soils, but there were strong soil and ecotypespecific differences with respect to the activity of different Ascomycete genera. Phialocephala-annotated transcripts dominated in roots in acid bog soil, and many of these transcripts were upregulated in roots in the acid ecotype compared to limestone ecotype plants. In contrast, a very mixed group of Ascomycete genera were shown to be active in limestone soil-grown roots, with the highest level observed for Colletotrichum-annotated transcripts. Furthermore, Colletotrichum, a range of other Ascomycota genera, Basidiomycetes and Oomycetes showed higher levels of activity in limestone ecotype roots compared to acid ecotype roots on both soils. Lignin biosynthesis genes were upregulated on limestone soil, and on acid bog soil they were upregulated in acid ecotype compared to limestone ecotype plants. Our results imply a possible role of lignin biosynthesis in limiting fungal and Oomycete activity in roots in the acid ecotype compared to limestone ecotype plants, when grown in acid bog soil, perhaps induced by the root endophyte Phialocephala. As expected, AM-fungi were shown to be more active in the $\mathrm{pH} 7.5$ mineral limestone soil compared to the $\mathrm{pH} 3.5$ organic acid bog soil, and this was the case in roots of both plant ecotypes. The same applied to a range of other Ascomycete genera, including Colletotrichum. The transcriptomics data suggested that both AM and non-AM fungi of some Ascomycota genera may play a role in $\mathrm{P}$ and Fe nutrition in the limestone soil, while other non-AM Ascomycota, in particular Phialocephala-related organisms, may aid plant $\mathrm{N}$ and $\mathrm{K}$ nutrition and increase tolerance to metal(loid) ions in the acid bog soil. In $H$. lanatus shoots, fungal transcripts were predominantly Ascomycete annotated and showed low levels of activity, with numbers slightly higher in acid bog compared to limestone quarry soil-grown shoots, corroborating the observation that there was no systemic fungal disease in the plants at the time of harvest. Our meta-transcriptome analyses provided insights into the functional and taxonomic eukaryotic microbiota community composition 
and interaction within two contrasting $H$. lanatus ecotypes. With natural multi-species eukaryotic plant microbiomes so far poorly characterized, our results in this particularly stress resistant and phenotypically plastic plant species outline a novel approach towards a more holistic study of edaphic stress adaptation.

\section{Additional files}

Additional file 1: Description of additional RNA-Seq data obtained from 3 hydroponically grown plants that were integrated into the Holcus lanatus metatranscriptome assembly. (DOCX $17 \mathrm{~kb}$ )

Additional file 2: Elemental composition, $\mathrm{pH}$ and loss on ignition (Lol) of acid bog and limestone quarry soils. (DOCX $20 \mathrm{~kb}$ )

Additional file 3: The meta-transcriptome assembly: The number of assembled plant and microbial transcripts with KOG annotations. (DOCX 21 kb)

Additional file 4: Significant DAVID GO enrichment results obtained for the 16 up-regulated and down-regulated plant gene lists. (XLSX $121 \mathrm{~kb}$ )

Additional file 5: Extended REViGO results for the 16 up-regulated and down-regulated plant gene lists. (XLSX 68 kb)

Additional file 6: Selected plant expressed gene results, for those genes discussed in the text. The table contains the following information for selected plant-assigned transcripts that are discussed in the text: 1) Plant root/shoot (for reported DESeq2 pairwise comparison); 2) Transcript ID; 3) gene description; 4) function; 5) possible role; 6) relevant reference (citations for relevant references are contained in Additional file 7); 7) DESeq2 result: $\mathrm{Al}-\mathrm{v}-\mathrm{LI}=\mathrm{Acid}$ bog soil limestone ecotype versus Limestone soil limestone ecotype, $\mathrm{Aa}-\mathrm{V}-\mathrm{Al}=\mathrm{Acid}$ bog soil acid ecotype versus Acid bog soil limestone ecotype, La-v-LI = Limestone soil acid ecotype versus Limestone soil limestone ecotype; 8) Two columns to indicate whether the transcript was significantly upregulated in acid or limestone soil and/ or acid or limestone ecotype. (XLSX $23 \mathrm{~kb}$ )

Additional file 7: Additional references cited in Additional file 6 and Additional file 11. (DOCX $32 \mathrm{~kb}$ )

Additional file 8: Plant-assigned transcripts, full results table, annotation and DESeq2 analysis. The table contains the following information for each expressed plant-assigned transcript: 1) The annotation of transcripts: this includes functional annotation (KOG class, KOG group, KOG definition) and best BLAST match against plant-refseq (match accession number, match description, percentage ID, BLAST score, length of alignment and percentage sequence coverage); 2) The full DESeq2 result for each pairwise comparison in shoot (list 1-4) and root (list 5-8): these columns contain the $\log _{2}$ foldchange and adjusted $P$ value (FDR) for pairwise comparisons. Pairwise comparisons are coded as follows: soil ( $A=$ acid bog soil, $L=$ limestone quarry soil), plant ecotype ( $a=$ acid bog plant ecotype, I = limestone quarry plant ecotype) in shoots and roots: Shoot Aa-v-La = Acid bog soil acid ecotype versus Limestone soil acid ecotype, Shoot Al-v-LI = Acid bog soil limestone ecotype versus Limestone soil limestone ecotype, Shoot Aa-v-Al=Acid bog soil acid ecotype versus Acid bog soil limestone ecotype, Shoot La- $\mathrm{V}-\mathrm{LI}=$ Limestone soil acid ecotype versus Limestone soil limestone ecotype, Root Aa-v-La = Acid bog soil acid ecotype versus Limestone soil acid ecotype, Root Al-v-LI = Acid bog soil limestone ecotype versus Limestone soil limestone ecotype, Root Aa-v-Al = Acid bog soil acid ecotype versus Acid bog soil limestone ecotype, Root La-V-LI = Limestone soil acid ecotype versus Limestone soil limestone ecotype; 3) The count table; 4) Additional BLAST annotations showing the best BLAST match against Arabidopsis lyrata, Arabidopsis thaliana and Brachypodium distachyon databases (sequence length, match accession number, e-value, percentage ID, BLAST score and length of alignment). (XLSX 18037 kb)
Additional file 9: Plant transcripts in fasta format. Transcript-ids in the fasta file correspond to those described in Additional file 8. Compressed .tar.gz text file. (GZ $8552 \mathrm{~kb}$ )

Additional file 10: Additional $q P C R$ information. Targets and primers used for qPCR and comparison of results obtained with RNA-Seq and qPCR. (DOCX $22 \mathrm{~kb})$

Additional file 11: Selected fungal annotated transcript results, including those discussed in the text. The table contains the following information for selected microbial assigned transcripts that are expressed in Holcus lanatus roots, many of which discussed in the text: 1) Transcript ID; 2) Best BLAST match (taxonomic division, genus and gene description); 3) KOG annotations (KOG ID, KOG group, KOG class, KOG definition); 4) possible role; 5) relevant reference (citations for relevant references are contained in Additional file 7); 6) two columns to indicate whether the transcript was significantly upregulated in acid or limestone soil, acid or limestone ecotype; 7) The full DESeq2 result for each root pairwise comparison: these columns contain the $\log _{2}$ foldchange and adjusted $P$ value (FDR) for root pairwise comparisons. Pairwise comparisons are coded as follows: soil $(A=$ acid bog soil, $L=$ limestone quarry soil), plant ecotype ( $a=$ acid bog plant ecotype, $I$ = limestone quarry plant ecotype): Root Aa-v-La = Acid bog soil acid ecotype versus Limestone soil acid ecotype, Root Al-v-LI = Acid bog soil limestone ecotype versus Limestone soil limestone ecotype, Root Aa-v-Al=Acid bog soil acid ecotype versus Acid bog soil limestone ecotype, Root La-V-LI = Limestone soil acid ecotype versus Limestone soil limestone ecotype. (XLSX $35 \mathrm{~kb}$ )

Additional file 12: Microbial-assigned transcripts, full results table, annotation and DESeq2 analysis. Description of File: The table includes information on expressed microbial transcripts. 1) Phylogenetic annotation of each transcript; 2) Whether significantly expressed in root acid bog soil (RA), root limestone soil (RL), shoot acid bog soil (SA) and/or shoot limestone soil (SL). Significantly expressed transcripts is defined as the number of microbial annotated transcripts that obtained $\geq 5$ aligned reads in at least 3 samples in each of the treatments RA (total 8 samples), RL (total 9 samples), SA (total 10 samples), SL (total 9 samples); 3) two columns indicating whether the transcript is "upregulated in acid or limestone ecotype in acid bog soil" and/or "upregulated in acid or limestone ecotype in limestone soil" 4) KOG functional annotation (KOG ID, KOG definition, KOG class, KOG group) and best BLAST match (sequence length, database that contained the best match, accession number, gene description, best match organism, e-value, percentage ID, BLAST score, percentage sequence coverage); 5) The full DESeq2 result for each pairwise comparison in shoot (list 1-4) and root (list 5-8): these columns contain the $\log _{2}$ foldchange and adjusted $P$ value (FDR) for pairwise comparisons. Pairwise comparisons are coded as follows: soil ( $A=$ acid bog soil, $L=$ limestone quarry soil), plant ecotype ( $a=$ acid bog plant ecotype, I = limestone quarry plant ecotype), shoots and roots (Shoot, Root), see sheet "DESeq2 pairwise comparisons" for further explanation of the 8 pairwise comparisons; 6) The count table. (XLSX 6498 kb)

Additional file 13: Significantly expressed and KOG annotated Basidiomycete transcripts in roots and shoots in each soil. The number of significantly expressed and KOG annotated Basidiomycete transcripts (All) is defined as the number of transcripts that obtained $\geq 5$ aligned reads in at least 3 samples from each of the following treatments: root acid bog soil (RA), root lime soil (RL), shoot acid bog soil (SA) and shoot lime soil (SL). Significant ecotype effects (absolute $\log _{2} F C \geq 1$ or $\leq-1$, FDR $<0.05$ ) as identified by DESeq2 analysis are reported in subsequent columns for each treatment group, under the heading plant effect. (DOCX $27 \mathrm{~kb}$ )

Additional file 14: Significantly expressed and KOG annotated Glomeromycotina transcripts in root and shoot in each soil. The number of significantly expressed and KOG annotated Glomeromycotina transcripts (All) is defined as the number of transcripts that obtained $\geq 5$ aligned reads in at least 3 samples from each of the following treatments: root acid bog soil (RA), root lime soil (RL), shoot acid bog soil (SA) and shoot lime soil (SL). Significant ecotype effects (absolute $\log _{2} F C \geq 1$ or $\leq-1, F D R<0.05$ ) as identified by DESeq2 analysis are 
reported in subsequent columns for each treatment group, under the heading plant effect. (DOCX $27 \mathrm{~kb}$ )

Additional file 15: Microbial transcripts in fasta format. Transcript-ids in the fasta file correspond to those described in Additional file 12. Compressed .tar.gz text file. (GZ $2398 \mathrm{~kb}$ )

Additional file 16: Colonization percentages of AM hyphae, non-AM hyphae, arbuscules and vesicles, in acid bog and limestone quarry ecotypes of $\mathrm{H}$. lanatus, grown in a reciprocal soil transplantation design. ( $A=$ acid bog soil, $L=$ limestone quarry soil), plant ecotype $(a=$ acid bog plant ecotype, I = limestone quarry plant ecotype). (DOCX $18 \mathrm{~kb}$ )

Additional file 17: $A M$ and non-AM fungal structures of stained $H$. lanatus roots of $(a, b)$ acid bog ecotype on acid bog soil; $(c, d)$ limestone quarry ecotype on acid bog soil; (e, f) acid bog ecotype on limestone quarry soil; $(g, h)$ limestone quarry ecotype on limestone quarry soil. (DOCX $93871 \mathrm{~kb})$

\section{Abbreviations}

A: Acid bog soil; Aa: Acid ecotype grown on acid bog soil; Al: Limestone ecotype on acid bog soil; AM: Arbuscular mycorrhiza/l; ANOVA: Analysis of variance; Arf1: GTP-binding ADP-ribosylation factor; BLASTx: Basic local alignment search tool; bp: Base pairs; cDNA: Complementary deoxyribonucleic acid; DAMPS: Damage-induced molecular patterns; DEGs: Differentially expressed genes; DNA: Deoxyribonucleic acid; FDR: False discovery rate; GLM: General linear models; GO: Gene Ontology; ICPMS: Inductively coupled plasma mass spectrometry; JA: Jasmonic acid; JGl: The Genome Portal of the Department of Energy Joint Genome Institute; KOG: EuKaryotic Orthologous Groups; KUP1: Potassium transporter 1; L: Lime stone quarry soil; La: Acid ecotype on limestone soil; LI: Limestone ecotype on limestone soil; $\log _{2}$ FC: Log $_{2}$ fold change; LUX: Luminous flux per unit area; NCBI: National Center for Biotechnology Information; NGS: Next-generation sequencing; Nr: Non-redundant; PAMPS: Pathogen-associated molecular patterns; PEPR2: Plasma membrane leucine-rich repeat receptor kinase 2; pmPOX2b: Plasma membrane-bound peroxidase 2b; PRRs: Pattern recognition receptors; PT: Phosphate transporter; qPCR: Quantitative polymerase chain reaction; RA: Root acid bog soil; RefSeq: Reference sequence; RL: Root limestone soil; RNA: Ribonucleic acid; RNA-Seq: Ribonucleic acid sequencing; Rpm: Revolutions per minute; RT: Reverse transcription; SA: Shoot acid bog soil; SAc: Salicylic acid; SL: Shoot limestone soil

\section{Acknowledgements}

We thank the Department for Employment and Learning NI for funding the studentship. Illumina Sequencing was performed by the Earlham Institute, Norwich Research Park, Norwich, NR4 7UH, UK. We thank Dr. Tancredi Caruso for the advice regarding root staining and quantification and Dr. Fuquan Liu for the advice regarding RNA extraction.

\section{Funding}

Funding was provided by the Department for Employment and Learning NI. The funding body played no part in the design, collection, analysis or interpretation of the experiment or in the production of the manuscript.

\section{Availability of data and materials}

The RNA-Seq data (fastq files) is publicly available in ArrayExpress under accession E-MTAB-4014 at https://www.ebi.ac.uk/arrayexpress/E-MTAB-4014.

\section{Authors' contributions}

AAM and CM conceived and designed the overall study. EY conducted the microcosm experiment, molecular analysis and root staining. MC performed the mineral nutrient analysis. EY and CM performed the bioinformatics and statistical analysis. EY, AAM and CM interpreted the data and wrote the manuscript. All authors read and approved the final manuscript.

\section{Ethics approval and consent to participate}

Permission to sample plant and soil was granted by the National Trust, Northern Ireland and Peatlands Park, Dungannon, Northern Ireland.

\section{Consent for publication}

Not applicable.

\section{Competing interests}

The authors declare that they have no competing interests.

\section{Publisher's Note}

Springer Nature remains neutral with regard to jurisdictional claims in published maps and institutional affiliations.

Received: 5 November 2017 Accepted: 5 March 2018

Published online: 20 March 2018

\section{References}

1. Eckhard G, Horst W, Neumann E. Adaptation of plants to adverse chemical soil conditions. In: Marschner P, editor. Marschner's mineral nutrition of higher plants. 3rd ed. Amsterdam: Elsevier, Academic Press; 2012. p. 409-72.

2. Gigon A, Rorison I. Response of some ecologically distinct plant species to nitrate-nitrogen and to ammonium-nitrogen. J Ecol. 1972;60:93-102.

3. Rousk J, Baath E, Brookes PC, Lauber CL, Lazupone C, Caporaso JG, et al. Soil bacterial and fungal communities across a pH gradient in arable soil. The ISME Journal. 2010:4(10):1340-51.

4. Elliott DR, SJM C, Nwaishi F, Nilsson RH, Sen R. Bacterial and fungal communities in a degraded ombrotrophic peatland undergoing natural and managed re-vegetation. PLoS One. 2015;10:e0124726.

5. Helgason T, Fitter AH. Natural selection and the evolutionary ecology of the arbuscular mycorrhizal fungi (phylum Glomeromycota). J Exp Bot. 2009;60:2465-80.

6. Newsham KK. A meta-analysis of plant responses to dark septate root endophytes. New Phytol. 2011;190(3):783-93.

7. Grimoldi A, Kavanova M, Lattanzi F, Schnyder H. Phosphorus nutritionmediated effects of arbuscular mycorrhiza on leaf morphology and carbon allocation in perennial ryegrass. New Phytol. 2005;168:435-44.

8. van der Heijden MGA, Streitwolf-Engel R, Riedl R, Siegrist S, Neudecker A, Ineichen $\mathrm{K}$, et al. The mycorrhizal contribution to plant productivity, plant nutrition and soil structure in experimental grassland. New Phytol. 2006;172:739-52.

9. Tawaraya K, Hashimoto K, Wagatsuma T. Effect of root exudate fractions from P-deficient and P-sufficient onion plants on root colonisation by the arbuscular mycorrhizal fungus Gigaspora margarita. Mycorrhiza. 1998;8:67-70.

10. Chitarra W, Pagliarani C, Maserti B, Lumini E, Siciliano I, Cascone P, et al. Insights on the impact of arbuscular mycorrhizal symbiosis on tomato tolerance to water stress. Plant Physiol. 2016;171:1009-23.

11. Wang J, Li T, LiU G, Smith JM, Zhao Z. Unraveling the role of dark septate endophyte (DSE) colonizing maize (Zea mays) under cadmium stress: physiological, cytological and genic aspects. Sci Rep. 2016;6:22028.

12. Sarwat M, Hashem A, Ahanger MA, Abd Allah EF, Alqarawi AA, Alyemeni $\mathrm{MN}$, et al. Mitigation of $\mathrm{NaCl}$ stress by arbuscular mycorrhizal fungi through the modulation of osmolytes, antioxidants and secondary metabolites in mustard (Brassica juncea L.) plants. Front Plant Sci. 2016;7:869.

13. Rodriguez RJ, White JF Jr, Arnold AE, Redman RS. Fungal endophytes: diversity and functional roles. New Phytol. 2009:182:314-30.

14. Jiang Q, Zhuo F, Long S, Zhao H, Yang D, Ye Z, et al. Can arbuscular mycorrhizal fungi reduce $\mathrm{Cd}$ uptake and alleviate $\mathrm{Cd}$ toxicity of Lonicera japonica grown in Cd-added soils? Sci Rep. 2016;6:21805

15. von Uexküll HR, Mutert E. Global extent, development and economic impact of acid soils. Plant Soil. 1995;171:1-15.

16. Miya A, Albert $P$, Shinya $T$, Desaki $Y$, Ichimura $K$, Shirasu $K$, et al. CERK1, a LysM receptor kinase, is essential for chitin elicitor signaling in Arabidopsis. Proc Natl Acad Sci U S A. 2007;104:19613-8.

17. Yamaguchi Y, Huffaker A, Bryan AC, Tax FE, Ryan CA. PEPR2 is a second receptor for the Pep1 and Pep2 peptides and contributes to defense responses in arabidopsis. Plant Cell. 2010:22:508-22.

18. Williams B, Kabbage M, Kim H, Britt R, Dickman MB. Tipping the balance: Sclerotinia sclerotiorum secreted oxalic acid suppresses host defenses by manipulating the host redox environment. PLoS Pathog. 2011;7:e1002107.

19. Classen AT, Sundqvist MK, Henning JA, Newman GS, Moore JAM, Cregger MA, et al. Direct and indirect effects of climate change on soil microbial and soil microbial-plant interactions: what lies ahead? Ecosphere. 2015;6: 130. https://doi.org/10.1890/ES15-00217.1.

20. Blaalid R, Carlsen T, Kumar S, Halvorsen R, Ugland Kl, Fontana G, et al. Changes in root-associated fungal communities along a primary succession gradient analysed by 454 pyrosequencing. Mol Ecol. 2012;21(8):1897-908.

21. Van Geel M, Busschaert P, Honnay O, Lievens B. Evaluation of six primer pairs targeting the nuclear rRNA operon for characterisation of arbuscular 
mycorrhizal fungal (AMF) communities using 454 pyrosequencing. $J$ Microbiol Methods. 2014;106:93-100.

22. Langille MG, Zaneveld J, Caporaso JG, McDonald D, Knights D, Reyes JA, Clemente JC, Burkepile DE, Vega Thurber RL, Knight R, Beiko RG, Huttenhower C. Predictive functional profiling of microbial communities using 16S rRNA marker gene sequences. Nat Biotechnol. 2013;31(9):814-21.

23. Bordenstein SR, Theis KR. Host biology in light of the holobiome: 10 principles of holobiome and hologenomes. PLoS Biol. 2015;13:e1002226.

24. Busby PE, Soman C, Wagner MR, Friesen ML, Kremer J, Bennett A, Morsy M, Eisen JA, Leach JE, Dangl JL. Research priorities for harnessing plant microbiomes in sustainable agriculture. PLoS Biol. 2017;15(3):e2001793.

25. Cox JW, Ballweg RA, Taft DH, Velayutham P, Haslam DB, Porollo A. A fast and robust protocol for metataxonomic analysis using RNAseq data. Microbiome. 2017;5(1):7.

26. Rich MK, Courty PE, Roux C, Reinhardt D. Role of the GRAS transcription factor ATA/RAM1 in the transcriptional reprogramming of arbuscular mycorrhiza in Petunia hybrida. BMC Genomics. 2017;18(1):589.

27. Handa Y, Nishide H, Takeda N, Suzuki Y, Kawaguchi M, Saito K. RNA-seq transcriptional profiling of an arbuscular mycorrhiza provides insights into regulated and coordinated gene expression in Lotus japonicus and Rhizophagus irregularis. Plant Cell Physiol. 2015;56(8):1490-511.

28. De Cremer K, Mathys J, Vos C, Froenicke L, Michelmore RW, Cammue BP, De Coninck B. RNAseq-based transcriptome analysis of Lactuca sativa infected by the fungal necrotroph Botrytis cinerea. Plant Cell Environ. 2013;36(11):1992-2007.

29. Tan G, Liu K, Kang J, Xu K, Zhang Y, Hu L, et al. Transcriptome analysis of the compatible interaction of tomato with Verticillium dahliae using RNAsequencing. Front Plant Sci. 2015;6:428.

30. Lowe RGT, Cassin A, Grandaubert J, Clark BL, Van de Wouw AP, Rouxel T, et al. Genomes and transcriptomes of partners in plant-fungal-interactions between canola (Brassica napus) and two Leptosphaeria species. PLoS One. 2014;9:e103098.

31. Xu X, Wang C, Li S, Su Z, Zhou H, Mao L, et al. Friend or foe: differential responses of rice to invasion by mutualistic or pathogenic fungi revealed by RNAseq and metabolite profiling. Sci Rep. 2015:5:13624.

32. Ho C, Tan Y, Yeoh K, Ghazali A, Yee W, Hoh C. De novo transcriptome analyses of host-fungal interactions in oil palm (Elaeis guineensis Jacq.). BMC Genomics. 2016;17:66.

33. Beddows AR. Biological flora of the British Isles: Holcus lanatus L. J Ecol. 1961;49:421-30.

34. Bischoff A, Cremieux L, Smilauerova M, Lawson CS, Mortimer SR, Dolezal J, et al. Detecting local adaptation in widespread grassland species - the importance of scale and local plant community. J Ecol. 2006;94:1130-42.

35. Lande R. Adaptation to an extraordinary environment by evolution of phenotypic plasticity and genetic assimilation. J Evol Biol. 2009;22:1435-46.

36. López IF, Balocchi OA, Kemp PD, Valdes C. Phenotypic variability in Holcus lanatus L. in southern Chile: a strategy that enhances plant survival and pasture stability. Crop and Pasture Science. 2009;60:768-77.

37. Chen ZC, Yokosho K, Kashino M, Zhao F, Yamaji N, Ma JF. Adaptation to acidic soil is achieved by increased numbers of cis-acting elements regulating ALMT1 expression in Holcus lanatus. Plant J. 2013;76:10-23.

38. Meharg C, Khan B, Norton G, Deacon C, Johnson D, Reinhardt R, et al. Traitdirected de novo population transcriptome dissects genetic regulation of a balanced polymorphism in phosphorus nutrition/arsenate tolerance in a wild grass, Holcus lanatus. New Phytol. 2014;201:144-54.

39. Meharg AA, Bailey J, Breadmore K, Macnair MR. Biomass allocation, phosphorous nutrition and vesicular-arbuscular mycorrhizal infection in clones of Yorkshire Fog, Holcus lanatus L. (Poaceae) that differ in their phosphate uptake kinetics and tolerance to arsenate. Plant Soil. 1994; 160:11-20.

40. Sánchez Márquez S, Bills GF, Dominguez AL, Zabalgogeazcoa I. Endophytic mycobiota of leaves and roots of the grass Holcus lanatus. Fungal Divers. 2010;41:115-23

41. Kochian LV, Hoekenga OA, Pineros MA. How do crop plants tolerate acid soils? Mechanisms of aluminum tolerance and phosphorous efficiency. Annu Rev Plant Biol. 2004;55:459-93.

42. Signes-Pastor AJ, Carey M, Meharg AA. Inorganic arsenic in rice-based products for infants and young children. Food Chem. 2016;191:128-34.

43. McGonigle TP, Miller MH, Evans DG, Fairchild GL, Swan JA. A new method which gives an objective measure of colonization of roots by vesiculararbuscular mycorrhizal fungi. New Phytol. 1990;115:495-501.

44. Fastqc http://www.bioinformatics.babraham.ac.uk/projects/fastqc/.
45. seqtk, https://github.com/lh3/seqtk.

46. Fastq-mcf, https://expressionanalysis.github.io/ea-utils/.

47. Grabherr MG, Haas BJ, Yassour M, Levin JZ, Thompson DA, Amit I, et al. Fulllength transcriptome assembly from RNA-Seq data without a reference genome. Nat Biotechnol. 2011;29:644-52.

48. Camacho C, Coulouris G, Avagyan V, Ma N, Papadopoulos J, Bealer K, Madden TL. BLAST+: architecture and applications. BMC Bioinformatics. 2009;10:421.

49. Pruitt KD, Tatusova T, Maglott DR. NCBI reference sequences (RefSeq): a curated non-redundant sequence database of genomes, transcripts and proteins. Nucleic Acids Res. 2007;35(Database issue):D61-5.

50. plant-refseq (ftp://ftp.ncbi.nlm.nih.gov/refseq/release/plant). Release 71, accessed August 2015

51. protozoa-refseq (ftp://ftp.ncbi.nlm.nih.gov/refseq/release/protozoa). Release 71, accessed August 2015

52. fungi-refseq (ftp://ftp.ncbi.nlm.nih.gov/refseq/release/fungi). Release 72, accessed November 2015

53. Tian T, Liu Y, Yan H, You Q, Yi X, Du Z, et al. agriGO v2.0: a GO analysis toolkit for the agricultural community, 2017 update. Nucleic Acids Res. 2017 https://doi.org/10.1093/nar/gkx382. [Epub ahead of print]. AgriGO accessed in June 2015.

54. Grigoriev IV, Nordberg H, Shabalov I, Aerts A, Cantor M, Goodstein D, et al. The genome portal of the Department of Energy Joint Genome Institute. Nucleic Acids Res. 2012;40(Database issue):D26-32.

55. Grigoriev IV, Cullen D, Goodwin SB, Hibbett D, Jeffries TW, Kubicek CP, et al. Fueling the future with fungal genomics. Mycology. 2011;2(3):192-209.

56. Rawat V, Abdelsamad A, Pietzenuk B, Seymour DK, Koenig D, Weigel D, et al. Improving the annotation of Arabidopsis lyrata using RNA-Seq data. PLoS One. 2015;10(9):e0137391.

57. Tisserant E, Malbreil M, Kuo A, Kohler A, Symeonidi A, Balestrini R, et al. Genome of an arbuscular mycorrhizal fungus provides insight into the oldest plant symbiosis. Proc Natl Acad Sci U S A. 2013;110(50):20117-22.

58. Zhu S, Cao YZ, Jiang C, Tan BY, Wang Z, Feng S, et al. Sequencing the genome of Marssonina brunnea reveals fungus-poplar co-evolution. BMC Genomics. 2012;13:382. https://doi.org/10.1186/1471-2164-13-382.

59. O'Connell RJ, Thon MR, Hacquard S, Amyotte SG, Kleemann J, Torres MF, et al. Lifestyle transitions in plant pathogenic Colletotrichum fungi deciphered by genome and transcriptome analyses. Nat Genet. 2012;44(9):1060-5.

60. Morin E, Kohler A, Baker AR, Foulongne-Oriol M, Lombard V, Nagy LG, Ohm RA, et al. Genome sequence of the button mushroom Agaricus bisporus reveals mechanisms governing adaptation to a humic-rich ecological niche. Proc Natl Acad Sci U S A. 2012;109(43):17501-6.

61. Tyler BM, Tripathy S, Zhang $X$, Dehal $P$, Jiang $\mathrm{RH}$, Aerts $A$, et al. Phytophthora genome sequences uncover evolutionary origins and mechanisms of pathogenesis. Science. 2006;313:1261-6.

62. Koonin EV, Fedorova ND, Jackson JD, Jacobs AR, Krylov DM, Makarova KS, et al. A comprehensive evolutionary classification of proteins encoded in complete eukaryotic genomes. Genome Biol. 2004;5(2):R7.

63. Langmead B, Salzberg S. Fast gapped-read alignment with Bowtie 2. Nat Methods. 2012;9:357-9.

64. Robinson MD, McCarthy DJ, Smyth GK. edgeR: a Bioconductor package for differential expression analysis of digital gene expression data. Bioinformatics. 2010;26(1):139-40.

65. non-redundant (nr) protein database ftp://ftp.ncbi.nlm.nih.gov/blast/db/ Accessed Aug 2016.

66. Love Ml, Huber W, Anders S. Moderated estimation of fold change and dispersion for RNA-seq data with DESeq2. Genome Biol. 2014;15(12):550.

67. Huang d W, Sherman BT, Lempicki RA. Systematic and integrative analysis of large gene lists using DAVID bioinformatics resources. Nat Protoc. 2009;4(1):44-57.

68. Ashburner M, Ball CA, Blake JA, Botstein D, Butler H, Cherry JM, et al. Gene ontology: tool for the unification of biology. Nat Genet. 2000;25(1):25-9.

69. Supek F, Bošnjak M, Škunca N, Šmuc T. REVIGO summarizes and visualizes long lists of gene ontology terms. PLoS One. 2011;6(7):e21800.

70. Warnes GR, Bolker B, Lumley T. gplots: various R programming tools for plotting data. R package version 2.6.0. https://cran.r-project.org/web/ packages/gplots.

71. Oliveros JC. Venny. An interactive tool for comparing lists with Venn's diagrams. 2007-2015. http://bioinfogp.cnb.csic.es/tools/venny/index.html

72. Oksanen J, Blanchet FG, Friendly M, Kindt R, Legendre P, McGlinn D, et al. Vegan: community ecology package. R package version 2r.4-5. 2017. https://cran.r-project.org/web/packages/vegan. 
73. Hoffman GE, Schadt EE. variancePartition: interpreting drivers of variation in complex gene expression studies. BMC Bioinformatics. 2016;17(1):483.

74. Jain M, Nijhawan A, Tyagi AK, Khurana JP. Validation of housekeeping genes as internal control for studying gene expression in rice by quantitative realtime PCR. Biochem Biophys Res Commun. 2006;345(2):646-51.

75. Singh LP, Gill SS, Tuteja N. Unraveling the role of fungal symbionts in plant abiotic stress tolerance. Plant Signal Behav. 2011;6:175-91.

76. Rasmann S, Bennett A, Biere A, Karley A, Guerrieri E. Root symbionts: powerful drivers of plant above- and belowground indirect defenses. Insect Sci. 2017; https://doi.org/10.1111/1744-7917.12464.

77. Hardham AR, Blackman LM. Molecular cytology of Phytophthora-plant interactions. Australas Plant Pathol. 2009;39:29-35.

78. Ragel P, Rodenas R, Garcia-Martin E, Andres Z, Villalta I, Nieves-Cordones M, et al. The CBL interacting protein kinase CIPK23 regulates HAK5-mediated high-affinity K+ uptake in Arabidopsis roots. Plant Physiol. 2015;169:2863-73.

79. Kuć J. Compounds from plants that regulate or participate in disease resistance. CIBA Found Symp. 1990;154:213-24. 224-8. Review. PubMed PMID: 2086038

80. Frei M. Lignin: characterization of a multifaceted crop component ScientificWorldJournal. 2013;2013:436517.

81. Jumpponen A, Mattson KG, Trappe JM. Mycorrhizal functioning of Phialocephala fortinii with Pinus contorta on glacier forefront soil: interactions with soil nitrogen and organic matter. Mycorrhiza. 1998;7(5):261-5.

82. Tellenbach C, Sumarah MW, Grunig CR, Miller JD. Inhibition of Phytophthora species by secondary metabolites produced by the dark septate endophyte Phialocephala europaea. Fungal Ecol. 2013;6(1):12-8.

83. Cordier C, Pozo MJ, Barea JM, Gianinazzi S, Gianinazzi-Pearson V. Cell defense responses associated with localized and systemic resistance to Phytophthora induced in tomato by an arbuscular mycorrhizal fungus. Mol Plant-Microbe Interact. 1998;11:1017-28.

84. Gan P, Narusaka M, Kumakura N, Tsushima A, Takano Y, Narusaka Y, et al Genus-wide comparative genome analyses of Colletotrichum species reveal specific gene family losses and gains during adaptation to specific infection lifestyles. Genome Biol Evol. 2016;8(5):1467-81.

85. Hiruma K, Gerlach N, Sacristán S, Nakano RT, Hacquard S, Kracher B, et al. Root endophyte Colletotrichum tofieldiae confers plant fitness benefits that are phosphate status dependent. Cell. 2016;165(2):464-74.

86. Chapla VM, Zeraik ML, Leptokarydis IH, Silva GH, Bolzani VS, Young MC, et al. Antifungal compounds produced by Colletotrichum gloeosporioides, an endophytic fungus from Michelia champaca. Molecules. 2014;19(11):19243-52.

87. Summerell BA, Leslie JF, Liew ECY, et al. Fusarium species associated with plants in Australia. Fungal Divers. 2011;46:1-27.

88. Loeppert $\mathrm{RH}$. Reactions of iron and carbonates in calcareous soils. J Plant Nutr. 1986;9:195-214

89. Wang GM, Stribley DP, Tinker PB, Walker C. Effects of $\mathrm{pH}$ on arbuscular mycorrhiza I. Field observations on the long-term liming experiments at Rothamsted and Woburn. New Phytol. 1993;124:465-72.

90. Hazard C, Gosling P, van der Gast CJ, Mitchell DT, Doohan FM, Bending GD. The role of local environment and geographical distance in determining community composition of arbuscular mycorrhizal fungi at the landscape scale. ISME J. 2013;7(3):498-508.

91. Smith SE, Jakobsen I, Grønlund M, Smith FA. Roles of arbuscular mycorrhizas in plant phosphorus nutrition: interactions between pathways of phosphorus uptake in arbuscular mycorrhizal roots have important implications for understanding and manipulating plant phosphorus acquisition. Plant Physiol. 2011;156(3):1050-7.

92. Lehmann A, Rillig MC. Arbuscular mycorrhizal contribution to copper, manganese and iron nutrient concentrations in crops-a meta-analysis. Soil Biol Biochem. 2015;81:147-58.

93. Takahashi S, Yeo YS, Zhao Y, O'Maille PE, Greenhagen BT, Noel JP, et al. Functional characterization of premnaspirodiene oxygenase, a cytochrome P450 catalyzing regio- and stereo-specific hydroxylations of diverse sesquiterpene substrates. J Biol Chem. 2007;282:31744-54.

94. Whitney PA, Magasanik B. The induction of arginase in Saccharomyces cerevisiae. J Biol Chem. 1973;248(17):6197-202.

95. Paul $\mathrm{JH}$, Cooksey KE. Asparagine metabolism and asparaginase activity in a euryhaline Chlamydomonas species. Can J Microbiol. 1979;25(12):1443-51. PubMed PMID: 43771

96. Schlegel M, Münsterkötter $M$, Güldener U, Bruggmann R, Duò A, Hainaut $M$, et al. Globally distributed root endophyte Phialocephala subalpina links pathogenic and saprophytic lifestyles. BMC Genomics. 2016;17(1):1015.
97. Wong PTW, Dong C, Martin PM, Sharp PJ. Fairway patch-a serious emerging disease of couch (syn. bermudagrass) [Cynodon dactylon] and kikuyu (Pennisetum clandestinum) turf in Australia caused by Phialocephala bamuru P.T.W. Wong \& C. Dong sp. nov. Australas Plant Pathol. 2015;44(5):545-55.

98. Zeilinger S, Gupta VK, Dahms TE, Silva RN, Singh HB, Upadhyay RS, et al. Friends or foes? Emerging insights from fungal interactions with plants. FEMS Microbiol Rev. 2016:40(2):182-207.

99. Rodriguez RJ, Henson J, Van Volkenburgh E, Hoy M, Wright L, Beckwith F, et al. Stress tolerance in plants via habitat-adapted symbiosis. ISME J. 2008:2:404-16.

100. Rahman MH, Saiga S. Endophytic fungi (Neotyphodium coenophialum) affect the growth and mineral uptake, transport and efficiency ratios in tall fescue (Festuca arundinacea). Plant Soil. 2005;272:163-17.

\section{Submit your next manuscript to BioMed Central and we will help you at every step:}

- We accept pre-submission inquiries

- Our selector tool helps you to find the most relevant journal

- We provide round the clock customer support

- Convenient online submission

- Thorough peer review

- Inclusion in PubMed and all major indexing services

- Maximum visibility for your research

Submit your manuscript at www.biomedcentral.com/submit
) Biomed Central 